\title{
From Synoptic to Interdecadal Variability in Southern African Rainfall: Toward a Unified View across Time Scales
}

\author{
BENJAMIN POHL \\ Centre de Recherches de Climatologie, UMR 6282 Biogéosciences, CNRS/Université de Bourgogne \\ Franche-Comté, Dijon, France
}

\section{BASTIEN DIEPPOIS}

Centre for Agroecology, Water and Resilience, Coventry University, Coventry, United Kingdom, and Department of Oceanography, University of Cape Town, Cape Town, South Africa, and School of Geography, Earth and Environmental Sciences, University of Birmingham, Birmingham, United Kingdom

\section{JULIEN CRÉTAT}

Sorbonne Universités (UPMC, Univ Paris 06)-CNRS-IRD-MNHN, LOCEAN Laboratory, IPSL, Paris, and Laboratoire des Sciences du Climat et de l'Environnement, LSCE/IPSL, CEA-CNRS-UVSQ, Université Paris-Saclay, Gif-sur-Yvette, and Centre de Recherches de Climatologie, UMR 6282 Biogéosciences, CNRS/Université de Bourgogne Franche-Comté, Dijon, France

\section{DAMIAN LAWLER}

Centre for Agroecology, Water and Resilience, Coventry University, Coventry, United Kingdom

\section{MATHIEU ROUAULT}

Department of Oceanography, and Nansen-Tutu Center for Marine Environmental Research, University of Cape Town, Cape Town, South Africa

(Manuscript received 14 June 2017, in final form 30 April 2018)

\begin{abstract}
During the austral summer season (November-February), southern African rainfall, south of $20^{\circ} \mathrm{S}$, has been shown to vary over a range of time scales, from synoptic variability (3-7 days, mostly tropical temperate troughs) to interannual variability (2-8 years, reflecting the regional effects of El Niño-Southern Oscillation). There is also evidence for variability at quasi-decadal (8-13 years) and interdecadal (15-28 years) time scales, linked to the interdecadal Pacific oscillation and the Pacific decadal oscillation, respectively. This study aims to provide an overview of these ranges of variability and their influence on regional climate and large-scale atmospheric convection and quantify uncertainties associated with each time scale. We do this by applying $k$-means clustering onto long-term (1901-2011) daily outgoing longwave radiation anomalies derived from the 56 individual members of the Twentieth Century Reanalysis. Eight large-scale convective regimes are identified. Results show that 1) the seasonal occurrence of the regimes significantly varies at the lowfrequency time scales mentioned above; 2) these modulations account for a significant fraction of seasonal rainfall variability over the region; 3) significant associations are found between some of the regimes and the aforementioned modes of climate variability; and 4) associated uncertainties in the regime occurrence and convection anomalies strongly decrease with time, especially the phasing of transient variability. The shortlived synoptic anomalies and the low-frequency anomalies are shown to be approximately additive, but even if they combine their respective influence at both scales, the magnitude of short-lived perturbations remains much larger.
\end{abstract}

Corresponding author: Benjamin Pohl, benjamin.pohl@ubfc.fr 


\section{Introduction}

Our understanding of southern African (SA, south of $20^{\circ} \mathrm{S}$; acronyms summarized in appendix A) rainfall variability during austral summer [from November to February (NDJF)] has significantly increased over recent years. At the synoptic scale, the main rain-bearing systems are tropical temperate troughs (TTT; Todd and Washington 1999; Washington and Todd 1999; Todd et al. 2004; Fauchereau et al. 2009, hereafter F09; Hart et al. 2010; Ratna et al. 2013; Vigaud et al. 2012; Macron et al. 2014). These take the form of short-lived (typically 3-7 days), northwest-southeast-tilted convective cloud bands that link the tropics to the midlatitudes through interactions between extratropical Rossby waves and moisture convergence over SA (Hart et al. 2010; Macron et al. 2014). These systems account for $30 \%-60 \%$ of the seasonal precipitation totals (Hart et al. 2013; Macron et al. 2014). Other synoptic rainbearing systems can involve cut-off lows (Singleton and Reason 2007a,b), even though the latter are much more rare in austral summer than in other seasons (Favre et al. 2013). More regionally, in northeastern South Africa, southern Mozambique, and Botswana (in the later summer), mesoscale convective complexes (Blamey and Reason 2012) can contribute up to $20 \%$ of summer rainfall (Blamey and Reason 2013). There are also occasionally tropical cyclones or tropical low pressure systems associated with easterly waves (Dyson and Van Heerden 2001; Reason and Keibel 2004; Malherbe et al. 2012). Over the south coast of South Africa, nearly half of the annual rainfall results from ridging anticyclones (Engelbrecht et al. 2015). The Mascarene anticyclone over the southwest Indian Ocean and the Agulhas Current also play an important role in moisture transport onto the interior plateau. Intraseasonal SA rainfall variability, between 30 and 60 days, is of lesser importance for SA (Pohl et al. 2007; Oettli et al. 2014). It mostly relates to the Madden-Julian oscillation (MJO; Madden and Julian 1994; Zhang 2005), the dominant mode of tropical climate variability at this time scale. Synoptic to intraseasonal variability is of major importance for the region, since associated dry spells occurring during the austral summer rainy season (Tennant and Hewitson 2002; Cook et al. 2004; Usman and Reason 2004; Reason et al. 2005) have a strong impact on agriculture, water resources managers, and farmers. Their timing significantly controls crop yield and production (e.g., Masupha et al. 2016), since much of the rural population relies on rain-fed agriculture.

At the interannual time scale, SA rainfall is strongly driven by El Niño-Southern Oscillation (ENSO), especially since the late 1970s (Richard et al. 2000, 2001).
It promotes seasonal droughts with more frequent dry spells under El Niño conditions (Lindesay 1988; Reason et al. 2000; Reason and Jagadheesha 2005; Crétat et al. 2012; Dieppois et al. 2015). During La Niña, seasonal rainfall is usually above normal. The regional effects of El Niño are nonlinear (F09), with two similar events in the Pacific leading to different spatial patterns and intensity of SA rainfall anomalies, or sometimes no significant anomalies (Lyon and Mason 2007, 2009; Boulard et al. 2013). Associated mechanisms involve an eastward shift in the South Indian convergence zone (SICZ; Cook 2000) in response to warm sea surface temperature (SST) anomalies over the western Indian Ocean (Nicholson 1997; Nicholson and Kim 1997) or to atmospheric Rossby waves during El Niños (Cook 2001). Misra (2003) partly reconciled these two hypotheses by estimating that the spatial structure of SA rainfall anomalies depends mainly on regional Indian Ocean SST, while their amplitude is modulated by large-scale atmospheric Rossby waves.

(Multi)decadal variability, such as the interdecadal Dyer-Tyson cycle (18 years; Dyer and Tyson 1977) and the quasi-decadal time scale (10 years; Tyson 1981) can also modulate SA rainfall (Dyer and Tyson 1977; Mason and Jury 1997; Malherbe et al. 2012; Jury 2015): this has been interpreted as a chaotic resonance of interannual variability (Mason 1990; Kruger 1999; Reason and Rouault 2002). Using updated observational data, Dieppois et al. (2016, hereafter D16) have revisited the dominant modes of SA rainfall variability. They identified three significant time scales of variability in SA rainfall during both austral summer and winter seasons: interannual variability (Int.; 2-8 years), quasi-decadal variability (QDV; 8-13 years) mentioned above, and interdecadal variability (IDV; $15-28$ years). While the first time scale confirms the predominant influence of ENSO (Reason et al. 2000; Crétat et al. 2012; Philippon et al. 2012), QDV and IDV exhibit ENSO-like patterns interpreted as the signature of the interdecadal Pacific oscillation (IPO; Zhang et al. 1997; Power et al. 1999; Liu 2012; Dai 2013; Dong and Dai 2015) and the Pacific decadal oscillation (PDO; Mantua et al. 1997; Mantua and Hare 2002; Deser et al. 2004), respectively. These large-scale forcings all act to shift the SICZ (in an abnormally eastward location under warm conditions in the Pacific), hence potentially modifying the preferential location for TTT.

At each time scale, these changes in SICZ activity are embedded in quasi-annular geopotential anomalies describing a southward shift in the midlatitude westerlies. These could be related to the canonical southern annular mode (SAM) pattern or ENSO-like anomalies in the Southern Hemisphere (Seager et al. 2003; Fogt and 
Bromwich 2006; L'Heureux and Thompson 2006; Pohl et al. 2010). The relationship with the SAM is likely to be stronger from February to March at the interdecadal time scale in accordance with Malherbe et al. (2014, 2016). This also suggests interactions between time scales, as proposed in Allan et al. (2003), who found a quasi-decadal (9-13 years) SST signal in the Indo-Pacific Ocean signal interacting with the quasi-biennial oscillation (QBO) and ENSO and correlated with SA rainfall.

In addition to the remote influence of these modes of large-scale climate variability, SA rainfall is also influenced by modes of variability located in the Atlantic and Indian sectors. In the Atlantic, so-called Benguela Niños are regional ocean-atmosphere coupled phenomena off Angola and northern Namibia in austral summers that can influence SA rainfall (Hansingo and Reason 2009). While Rouault et al. (2003, 2009) and Lutz et al. (2015) confined the impact of that oceanic region to coastal rainfall in Angola and northern Namibia, Hermes and Reason (2009) and Reason and Smart (2015) suggest that this mode is linked to rainfall over the whole of SA. The existence of a warming reported by Blamey et al. (2015) could indicate decadal variability, even though this issue is still open (Tim et al. 2015). In the Indian Ocean, the subtropical Indian Ocean dipole (SIOD; Behera and Yamagata 2001) is also related to southern Africa rainfall (Reason 2001, 2002; Morioka et al. 2012; Hoell et al. 2017). The Indian Ocean on its own can also modulate SA rainfall (Washington and Preston 2006), especially the nearby southwest Indian Ocean (SWIO; Reason 1998; Reason and Mulenga 1999). More locally, Mason (1995) and Reason and Mulenga (1999) also showed linkages on decadal time scales between Agulhas variability and SA summer rainfall.

Most of these studies have been devoted to the analysis of a given mode of variability and/or a given time scale. To date, the general picture of the modulation of transient variability by the lower-frequency climate background remains incomplete. The present study aims toward filling this gap and complementing previous findings by investigating the interactions between synoptic, interannual, and decadal time scales and their effects on daily SA rainfall variability, including dry spells and TTT-related rainfall events. Here, we seek to disentangle the intrinsic and combined roles of interannual to decadal large-scale climate variability in driving daily SA rainfall. This will also provide useful information for both environmental and societal impact studies. We also aim to improve our understanding of the role of short-lived rain-bearing systems (in terms of frequency, location, spatial pattern, or intensity) on the magnitude and spatial distribution of austral summer
SA rainfall and analyze how their intrinsic properties can be modulated by low-frequency climate variability.

This paper is organized as follows. Section 2 presents the datasets and the clustering methodology used for this work. Section 3 discusses the scale interactions modulating the seasonal occurrence of large-scale convective regimes and their relationship with rainfall variability. Section 4 clarifies the mechanisms underpinning such interactions. Section 5 summarizes the results, establishes the main conclusions, and identifies remaining uncertainties for future work.

\section{Data and methods}

\section{a. Data}

The Climatic Research Unit dataset, version 3.23 (CRU TS3.23), is used to estimate SA rainfall and validate the outgoing longwave radiation (OLR) as a proxy of SA rainfall at the seasonal time scale. This $0.5^{\circ} \times 0.5^{\circ}$ dataset is derived from monthly rainfall provided by $\sim 4000$ weather stations distributed around the world from 1901 to 2014 (Harris et al. 2014). Its quality over SA is extensively discussed by D16. As illustrated in Fig. 1a, the wettest months occur in austral summer in most of SA (especially in the northeast), and between May and August in the southwestern and coastal regions (centered on the western cape region). In this study, we only focus on austral summer rainfall either at the gridpoint scale or using the summer rainfall index (SRI). It is defined as area-averaged rainfall amounts over all grid points located in the irregular region where the wettest month of the year occurs between November and February inclusive (maroon in Fig. 1a; see D16 for more details).

Monthly SST data from the Extended Reconstructed SST (ERSST.v4; Huang et al. 2015) of the National Climatic Data Center (NCDC) are used for describing the large-scale climate background conditions modulating SA rainfall and analyzing teleconnections. The ERSST.v4 data are generated using in situ measurements from the Comprehensive Ocean-Atmosphere Data Set (COADS), release 2.5, which employs new bias adjustments, quality control procedures, and analysis methods allowing for a reconstruction of sparse data over a $2^{\circ} \times 2^{\circ}$ resolution grid. This dataset, available since 1854 but more reliable since 1880, does not use satellite data, ensuring time consistency over the whole time period. In particular, it is not affected by a cold SST bias induced by the use of satellites at the end of the twentieth century (Reynolds et al. 2002).

The central dataset is the Twentieth Century Reanalysis, version 2c (20CR herein; Compo et al. 2011). 
(a)
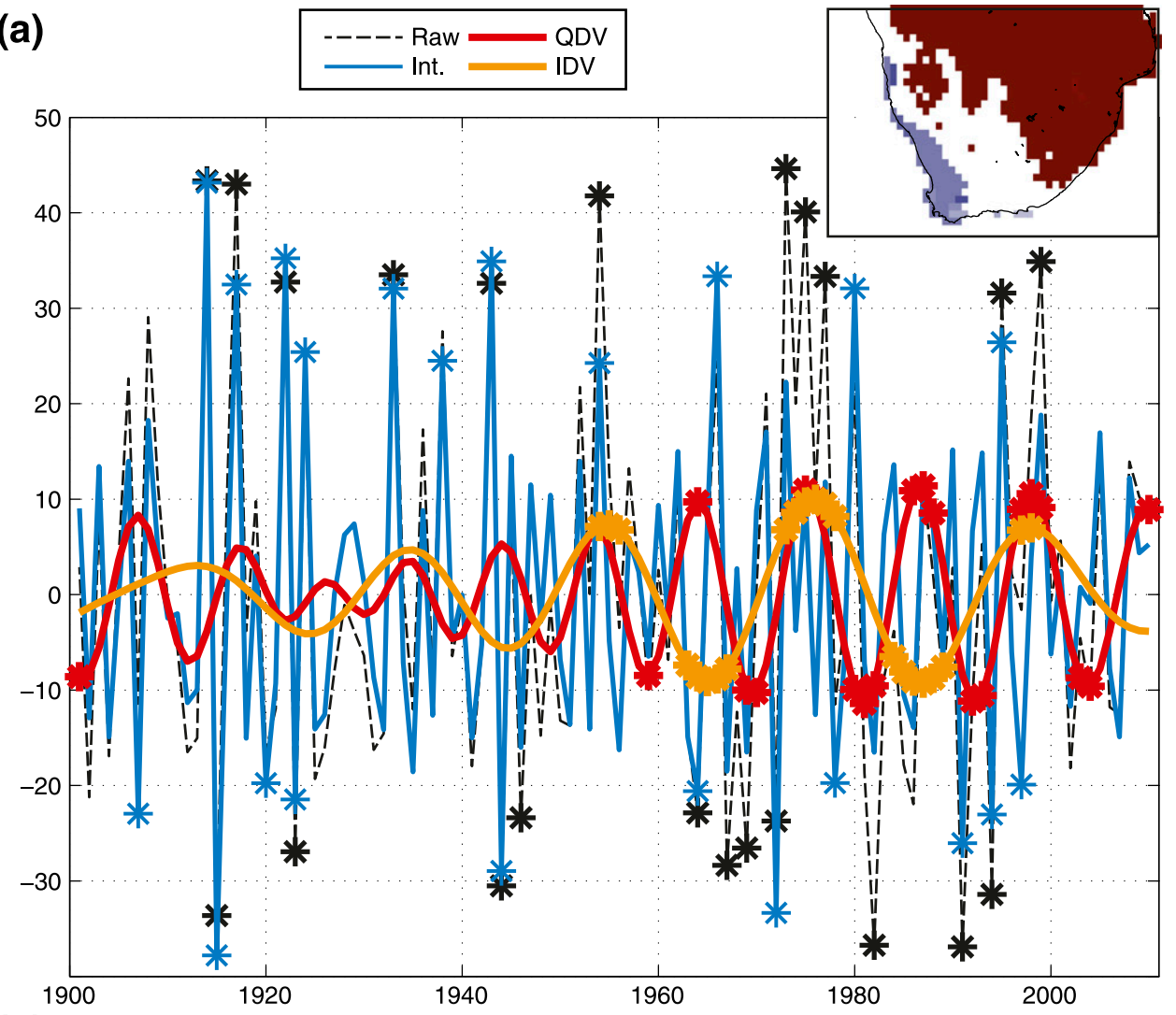

\section{(b) Raw}
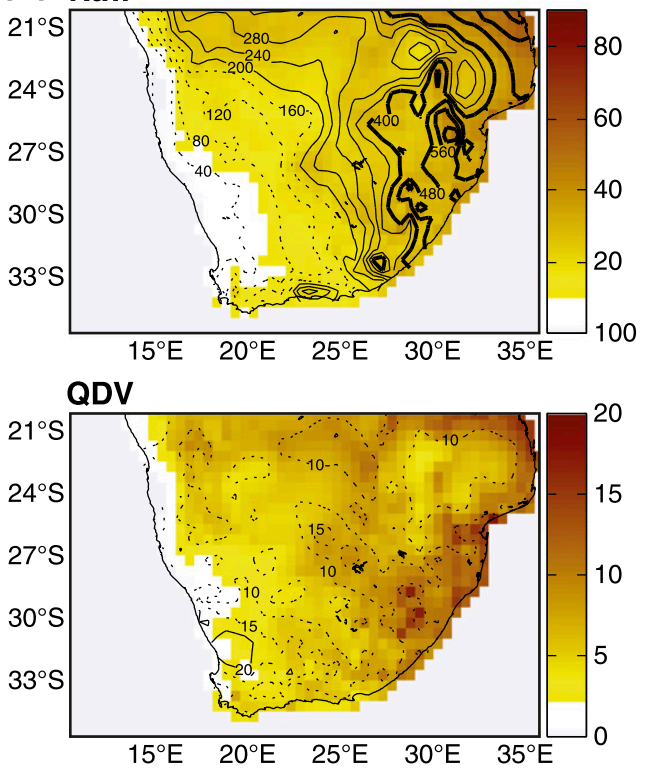

Interannual

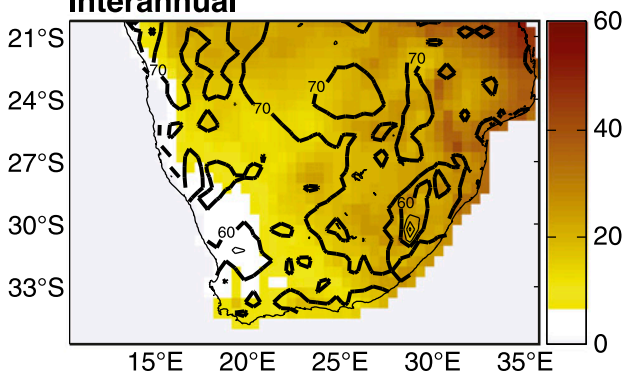

IDV

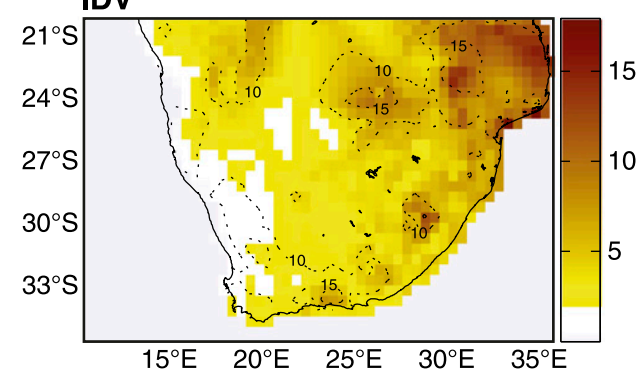

FIG. 1. (a) SRI (see details in D16) NDJF seasonal-mean anomalies (mm) derived from CRU monthly data, period 1901-2011: raw (unfiltered) and bandpass-filtered time series at the Int. (2-8 years), QDV (8-13 years), and IDV (15-28 years) time scales. Asterisks show the values below the 10th and above the 90th percentiles, used for composite analyses in section 4 . The region used to compute the SRI appears as red colors in the upper-right-side panel, while the region experiencing winter rainfall (WRI) appears in blue colors. (b) Standard deviation ( $\mathrm{mm} \mathrm{month}^{-1}$; colors) associated with each time scale. Note the different color scales for the different time scales. Black contours for raw fields show the seasonal-mean rainfall amounts (thick curves: above $400 \mathrm{~mm}$; dashed curves: below $200 \mathrm{~mm}$ ), and, for filtered fields, the fraction explained by each time scale against the raw SRI variance (\%). Dashed curves show percentages lesser than $20 \%$ (contour equidistance $5 \%$ ), thin curves percentages comprise between $20 \%$ and $50 \%$ (contour equidistance $10 \%$ ), and thick contours are for percentages above $50 \%$ (contour equidistance $10 \%$ ). 
(a) NOAA
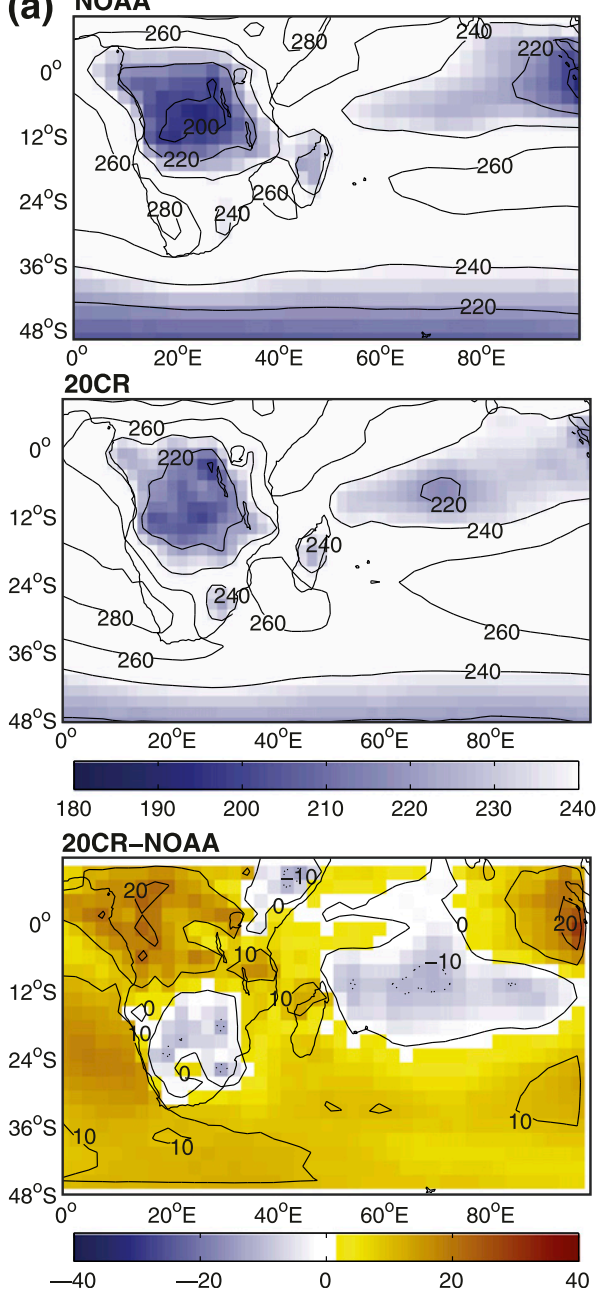
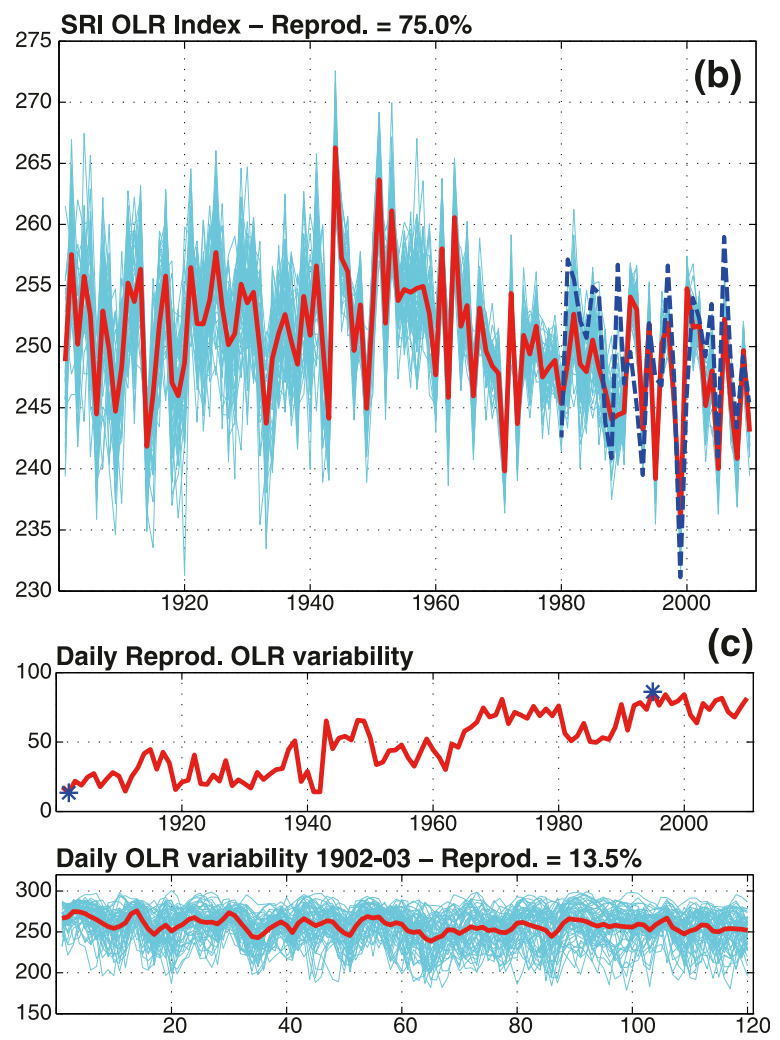

Daily OLR variability $1995-96-$ Reprod. $=86.2 \%$

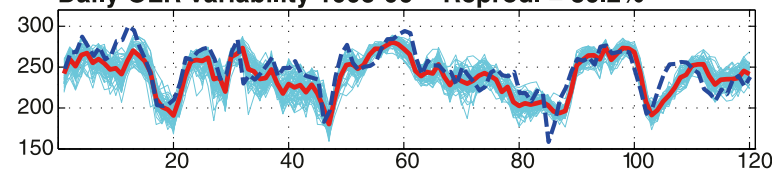

FIG. 2. (a) Shown in the upper panel is the austral summer seasonal-mean OLR $\left(\mathrm{W} \mathrm{m}^{-2}\right)$ according to the NOAA estimates, period NDJF 1979-2011. The middle panel is as in the upper panel, but for the 20CR ensemble mean. The lower panel shows 20CR biases against NOAA estimates. (b) Temporal evolution of seasonal-mean OLR over the SRI region for the 56 individual members of 20CR (cyan curves; their ensemble mean in red, with the fraction of reproducible variability labeled in the figure; period 1901-2011) and NOAA estimates (dashed blue curve; period 1979-2011). (c) Shown in the upper panel is the temporal evolution of the fraction of reproducible daily variability in NDJF OLR over the 1901-2011 period, according to the 56-member 20CR ensemble. See text for details. Asterisks denote the lowest and highest value. The middle panel shows daily OLR variability of the $5620 \mathrm{CR}$ individual ensemble members (cyan) and their ensemble mean (red) during the less reproducible season (NDJF; 1902-03). The lower panel is as in the middle panel, but for the most reproducible season (NDJF; 1995-96) between the 20CR members, together with the corresponding NOAA estimates (dashed blue).

The 20CR is a global, 56-member ensemble reanalysis, available from 1871 over a $2^{\circ} \times 2^{\circ}$ resolution grid. The 20CR is forced by monthly SST and sea ice distributions and assimilates surface pressure only for the entire period. While the quality of surface pressure and SST increases through the twentieth century (especially after the 1970s satellite era), this assimilation strategy reduces spurious trends and artificial breaks often found in multifield and time-varying assimilation systems (Poccard et al. 2000; Trenberth et al. 2001; Sturaro 2003; Kinter et al. 2004).
The following atmospheric variables from 20CR are used here: the 500-hPa geopotential height, the zonal and meridional components of the wind at 850 and $250 \mathrm{hPa}$, and, of primary importance for this paper, OLR, for determining recurrent synoptic convective regimes over SA. Since the OLR field strongly depends on the 20CR model physics, Fig. 2 assesses its quality against the NOAA satellite observations (Liebmann and Smith 1996).

Over SA and nearby SWIO, the spatial distribution of the seasonal-mean OLR is similar between NOAA and 
20CR (Fig. 2a), with active convection over the tropical Indian Ocean, the Congo basin, and, to a lesser extent, Madagascar and the Drakensberg in eastern South Africa. OLR values are generally larger by $5-10 \mathrm{~W} \mathrm{~m}^{-2}$ in the 20CR, except over subtropical SA, equatorial East Africa, and the central Indian Ocean. Temporally, seasonal-mean OLR area-averaged over the SRI region strongly varies at the interannual and decadal scales (Fig. 2b). Seasonal OLR derived from 20CR seems to show a negative trend since the 1950s, which has not been accompanied by similar long-term changes in seasonal rainfall totals. Over the common 1979-2010 period, the Pearson correlation between each 20CR ensemble member and the NOAA time series ranks between 0.80 and 0.92 (significant at 99\%). This indicates that 20CR accurately mimics the recent observed large-scale convective variability over $\mathrm{SA}$ at the seasonal time scale. A complementary way to estimate the reliability of the 20CR OLR is to examine the time evolution of its internal variability through the twentieth century by quantifying the spread within the 56-member ensemble. Following Pohl and Douville (2011) and Crétat et al. (2011), the fraction of reproducible (in phase) variability within an ensemble $X$ is given by the $\operatorname{ratio} f=\operatorname{var}(\bar{X}) / \operatorname{var}(X) \times 100$, where $\operatorname{var}(X)$ is the variance of the whole ensemble, and $\operatorname{var}(\bar{X})$ is the variance of the associated ensemble mean. Over the entire 1901-2011 period, $f=75 \%$. This value drops to $53 \%$ for the $1901-30$ period but increases to $88 \%$ for the 1981-2010 period. Very similar results were found at the daily time scale (Fig. 2c). This illustrates that the increased amount of surface pressure measurements assimilated in the 20CR allows for a more constrained and reproducible transient variability of convective activity at the intraseasonal time scale. In addition, comparing the $1902 / 03$ and 1995/96 austral summers, that is, the lowest $(14 \%)$ and largest $(86 \%) f$ values at the daily time scale, the phasing of day-to-day variability is both very reproducible and very realistic in 1995-96, as determined through the daily correlations with NOAA observations. Associations with seasonal rainfall show similar time evolution: correlation values computed with the seasonal OLR index are statistically significant for all members but increase throughout the century, especially since the mid1960s (not shown).

\section{b. $k$-means clustering}

Synoptic OLR-based convective regimes are obtained through a $k$-means clustering (Cheng and Wallace 1993; Michelangeli et al. 1995). This has already been successfully used to deconstruct ENSO influence over SA (F09), document the TTT life cycle (Vigaud et al. 2012; Macron et al. 2014), and assess its influence on rainfall over Madagascar and the nearby Mascarene Islands
(Macron et al. 2016). The method is appropriate to extract the recurrent configurations associated with strong anomalies in the input field (i.e., the anomaly patterns explaining the largest fraction of the overall original variance). In the present paper, $k$-means clustering is used to question to what extent the interannual, QDV, and IDV variability ranges identified in D16 modulate the occurrence and intrinsic property of these recurrent synoptic convective regimes.

This method is applied to daily NDJF OLR anomalies (i.e., mean annual cycle removed) of one single member (member 1 ) between 1900/01 and 2010/11 (i.e., 120 days $\times$ 110 years $=13200$ days) over the $10^{\circ}-40^{\circ} \mathrm{S}, 7.5^{\circ}-70^{\circ} \mathrm{E}$ domain (i.e., 544 grid points) usually utilized for TTT studies (e.g., Todd and Washington 1999; Washington and Todd 1999; Todd et al. 2004; F09; Pohl et al. 2009). A principal component analysis is applied to these NDJF OLR anomalies prior to the $k$-means clustering to filter out local convection and atmospheric noise. The PCAfiltered OLR anomalies account for $70 \%$ of the original variance in 35 eigenvectors. Following Michelangeli et al. (1995), the optimal number of clusters $k$ is determined using a red-noise test, which compares the "classifiability" of real input data against Markov-generated red-noise data having the same covariance matrix. Unlike F09, who identified $k=7$ as the optimal number of observed OLR clusters, here we find a partition into eight clusters reaching the $95 \%$ confidence level (not shown). Additional analyses (not shown) indicate that this difference is mostly related to the period considered; there is much more consistency between the 20CR and observed convective regimes for the overlapping years (1979-2011).

To quantify intermember uncertainties, the convective regimes are next calculated for members $2-56$. The daily OLR anomalies from these members are first projected onto the phase space described by the first 35 eigenvectors of member 1 . At this stage, each day of each member is thus characterized by its coordinates on these 35 Cartesian axes, instead of the 544 grid points of the domain. Second, the Euclidean distance $d$ between each observation (i.e., each day of each member) and each of the $k=8$ centroids of member 1 is computed, and each observation is assigned to the closest centroid by minimizing $d$. As successfully used in Crétat et al. (2015), this projection methodology forces the convective regimes to have similar spatial patterns across the members, but does not impose any temporal covariability: this facilitates discussion of the temporal uncertainties in the frequency of the regimes.

\section{c. Spectral filtering}

Scale interactions between synoptic convective regimes, monthly and seasonal rainfall, and SST anomalies 
are assessed by decomposing their respective variability onto the three time scales: interannual (2-8-years), QDV (8-13 years), and IDV (15-28 years). These data are bandpassed in the frequency domain with a fast Fourier transform (FFT) digital filter. The time series are detrended prior to the FFT filtering using a locally weighted linear regression (Wu et al. 2007; D16).

The raw and filtered (interannual, QDV, and IDV) SRI time series, shown in Fig. 1a, illustrate how the overall SA rainfall variability can be explained by the superposition of these time scales. The successive wet years of the 1970s and 1990s mainly result from additive (in phase) associations between QDV and IDV, while interannual variability clearly predominates before the 1950s. This questions the reliability of the CRU data for documenting early twentieth-century SA rainfall. This issue cannot be precisely quantified here, but the SRI region includes at least 40 stations over the period (D16). This also questions the robustness of the scale decomposition to the length of data considered, an issue discussed in appendix B. Figure $1 \mathrm{~b}$ shows that interannual variability explains most of the variance of the unfiltered time series $(\sim 60 \%-70 \%)$ independently from the region considered, while the contribution of QDV and IDV $(\sim 20 \%-25 \%$ and $\sim 15 \%-20 \%$, respectively) is much weaker, albeit nonnegligible. These values constitute a caveat in interpreting the results presented below: for instance, even if one given mode of variability explains a very large fraction of interdecadal variability, it only accounts for from a sixth to a fifth of the variance of raw SA rainfall since 1900.

\section{Interannual to interdecadal fluctuations of synoptic convective regimes}

In this section we discuss the large-scale convective regimes, their associations with SA rainfall, and their temporal variability, as inferred by their seasonal occurrence.

\section{a. Eight daily convective regimes}

Figure 3a presents the daily mean OLR anomalies associated with the eight $20 \mathrm{CR}$ convective regimes for member 1, which have been reordered to match the regimes presented in previous studies (F09; Macron et al. 2014, 2016; Vigaud et al. 2012). Circulation anomalies associated with these regimes, together with their typical life cycle, persistence, and propagative properties, are discussed in these papers. This section briefly discusses the regimes to help interpret them in the remainder of the paper and focuses on their association and upscaling effects with low-frequency variability in SA.
As in F09, large-scale daily convection is almost equally distributed in the different synoptic regimes (seven out of eight $20 \mathrm{CR}$ regimes each accounting for $\sim 10 \%-15 \%$ of the 13200 days studied). Clear-sky conditions or weak convection occur $\sim 25 \%$ of the time over most of SA (regimes 1 and 2), and active convection for the remaining $75 \%$ mostly concerns smaller regions with strong zonal gradients. Table 1 shows the typical persistence of the regime sequences and reveals that these eight regimes should be primarily interpreted as synoptic regimes. Their decorrelation time (i.e., the period beyond which the regime occurrence is not significantly autocorrelated at the $95 \%$ confidence level) ranges between 1 and 2 days on average, but is mostly less than or equal to 1 day and never exceeds 9 days. Thus, even when applied on long-term reanalyses, the $k$-means extracts short-lived regime sequences. This result differs from that of Pohl and Fauchereau (2012) over Antarctica using the same methodology.

Regime 1 describes an anomalously northward position of the ITCZ with convection weakened in the southern part of SA but strengthened in East Africa and the western tropical Indian Ocean, north of Madagascar. This meridional dipole is much stronger in the $20 \mathrm{CR}$ than the observations, with overestimated intensity and spatial coverage of active convection over the tropical Indian Ocean. This difference is similar when the 19792011 period is considered (not shown), suggesting that it relates to the model physics. Regime 2 is among the rarest and materializes an eastward shift in the SICZ with dry conditions over SA and a northwest-southeast band of active convection southeast of Madagascar, consistent with F09 and Macron et al. (2016). Regime 3 differs between the 20CR and the observations. In the observations (F09), it shows increased convection over the SA landmass (south of $10^{\circ} \mathrm{S}$ ) interpreted as a general southward extension of the continental ITCZ. In the 20CR, it describes a zonal dipole in landmass convection with negative (positive) OLR anomalies in the western (eastern) subtropical SA. This may relate to a westward shift in the Angola low (see, e.g., Mulenga et al. 2003; Cook et al. 2004; Reason and Jagadheesha 2005; Munday and Washington 2017). Such a difference persists when considering seven instead of eight convective regimes in the 20CR for both the 1901-2011 and 19792011 periods (not shown). Regime 4 describes increased convection over and near SA, south of $20^{\circ} \mathrm{S}$, and decreased convection in tropical SA. This regime represents the influence of midlatitude disturbances on SA convection. It is associated with a deep temperate trough southwest of SA and can be considered as a robust precursor of TTT (F09; Macron et al. 2014). The remaining regimes (5-8) represent tropical-temperate 
(a)
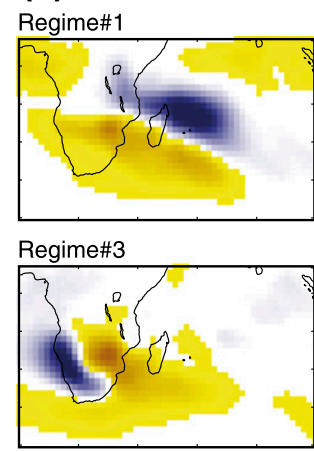

Regime\#5

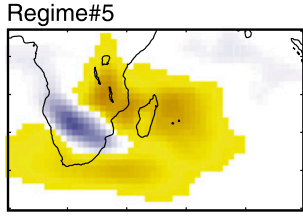

Regime\#7
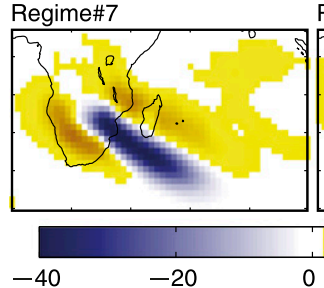

(c)

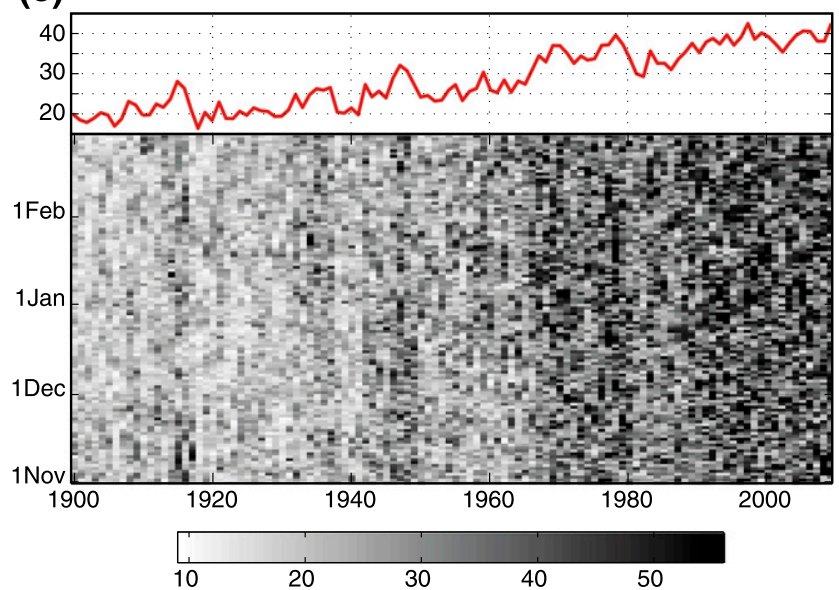

Regime\#2

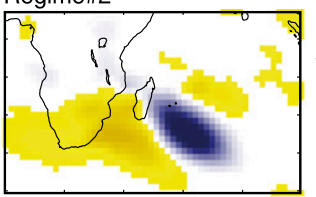

Regime\#4

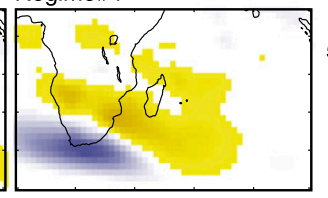

Regime\#6

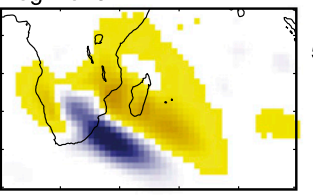

Regime\#8

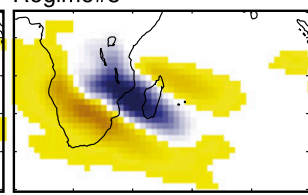

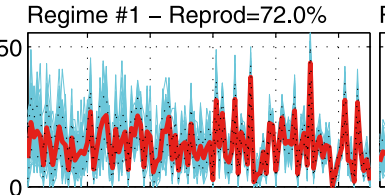

$0 \frac{19201940196019802000}{1920}$

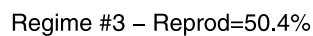

50

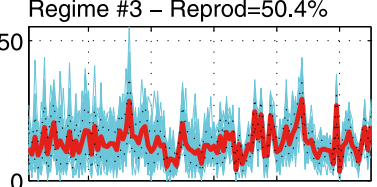

$0 \frac{19201940196019802000}{1920}$

Regime \#5 - Reprod $=67.2 \%$

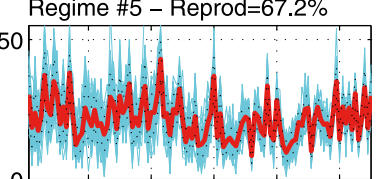

$0 \quad \frac{i}{19201940196019802000} 19201940196019802000$
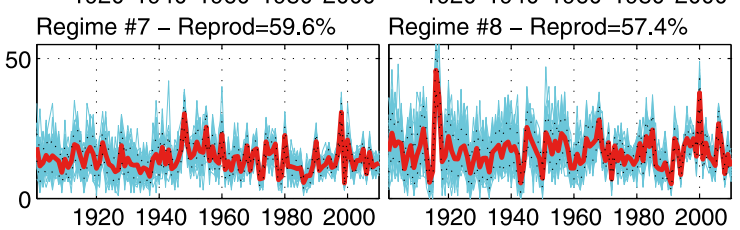

Regime \#2 - Reprod=57.3\%

19201940196019802000

Regime \#4 - Reprod=61.8\%

Regime \#6 - Reprod=62.8\%

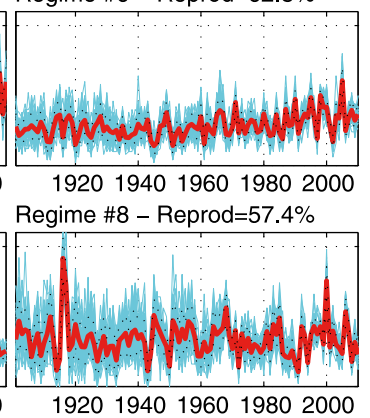

(b)

(d)

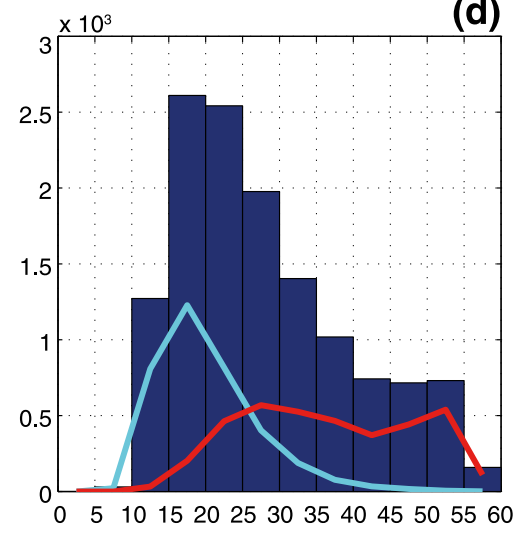

FIG. 3. (a) OLR anomalies calculated after removal of the mean annual cycle $\left(\mathrm{W} \mathrm{m}^{-2}\right)$ for each convective regime derived from a $k$-means analysis applied over the first member of 20CR, period NDJF 1901-2011. Only anomalies that are significant at the $95 \%$ significance level according to a $t$ test are displayed. (b) Number of seasonal occurrences of each convective regime for the 56 ensemble members of 20CR (cyan curves), after projecting each day of each member onto the nearest centroid derived from the first member. The red curve shows the ensemble mean, and the fraction of reproducible variability is labeled in the figure for each regime. (c) For each day ( $y$ axis) of each austral summer ( $x$ axis) of the period 1901-2011, number of members (out of 56) ascribed to the same centroid. The red curve shows the seasonal-mean intermember agreement averaged over each NDJF season. (d) Histogram of the intermember agreement [number of days ( $y$ axis) against the number of convergent members ( $x$ axis)] for periods 1901-2011 (bars), 1901-30 (cyan curve), and 1981-2010 (red curve). 
TABLE 1. Persistence of the regime occurrences, period NDJF 1901-2011, as inferred by the decorrelation time of the associated occurrence series (i.e., the number of days required for the serial correlation to become statistically insignificant). For each regime are presented statistics (minimum, median, average, maximum, and standard deviation $\sigma$ ) of the persistence from one year to another.

\begin{tabular}{|c|c|c|c|c|c|c|c|c|}
\hline & Regime 1 & Regime 2 & Regime 3 & Regime 4 & Regime 5 & Regime 6 & Regime 7 & Regime 8 \\
\hline Min & 0 & 0 & 0 & 0 & 1 & 0 & 0 & 0 \\
\hline Median & 1 & 1 & 1 & 1 & 1 & 1 & 1 & 1 \\
\hline Mean & 1.54 & 1.17 & 1.35 & 1.07 & 1.46 & 1.00 & 1.13 & 1.54 \\
\hline Max & 8 & 3 & 3 & 2 & 3 & 2 & 2 & 5 \\
\hline$\sigma$ & 1.16 & 0.49 & 0.60 & 0.38 & 0.57 & 0.19 & 0.39 & 0.78 \\
\hline
\end{tabular}

interactions with northwest-southeast-tilted bands of active convection, which differ according to their meridional extension and zonal location. Regime 5, which is the most frequent $20 \mathrm{CR}$ regime, is thought to be the early stage and/or the westernmost location of TTT, with deep convection confined to the tropical latitudes [see also Macron et al. $(2014,2016)$ for a physical interpretation of this regime]. Regimes 6 and 7 describe mature TTT with strong tropical-temperate interactions and active convection over central and western SA, consistent with F09, Vigaud et al. (2012), and Macron et al. (2014). Regime 8 documents the easternmost location and/or decaying phase of TTT, with no obvious continuity between the tropics and the midlatitudes in the enhanced convection band. While not perfect, the 20CR represents the main salient synoptic regimes of observed large-scale daily convection discussed in previous studies.

Figure $3 \mathrm{~b}$ presents the number of seasonal occurrences of each 20CR regime for the 56 members. The reproducible fraction of the regime variability ranks from $50 \%$ to $60 \%$ for the wettest regimes and up to $72 \%$ for the driest. This confirms that dry spells tend to be more reproducible than wet spells (e.g., Crétat et al. 2011). As for the OLR index shown in Fig. 2, the intermember uncertainties decrease through the twentieth century because of the gradual increase in the density of surface pressure measurements. The decrease in the intermember spread is even more evident at the daily time scale, when counting the number of members ascribed to the same regime (Fig. 3c). Over the whole period, the typical agreement between ensemble members lies between 15 and 30 inphase members (Fig. 3d). The modal value is weaker during the early decades, but the range of in-phase members spreads much more and increases for the recent period (Fig. 3d). While generally improved by the larger amount of data assimilated, the reproducibility of largescale convection still remains highly sensitive to the strength of the synoptic forcing over SA and nearby SWIO regions (Crétat et al. 2011; Crétat and Pohl 2012).

The interannual to interdecadal periodicities in the seasonal occurrence of each regime is next examined through power spectrum analysis and compared to the spectrum of the SRI (not shown). As stated in D16, the SRI shows significant periodicities at the interannual (2-8 years), quasi-decadal (8-13 years), and interdecadal (15-28 years) time scales. All convective regimes also peak at the interannual time scale, with moderate to large reproducibility between the members but marked differences in the periodicity peaks from one regime to another. Regimes 1, 4, 6, and 8 have significant periodicities between 2 and 5 years, similar to the SRI. Regime 5 peaks at 5-6 years, and regimes 2, 3, and 7 show larger uncertainties, with less reproducible results from one ensemble member to another.

Results are much noisier for QDV, except for regimes $2,3,4$, and 5 , which exhibit clear quasi-decadal periodicities. Regime 6 , in contrast, shows no significant peak at these time scales, while the situation is more contrasted between the ensemble members for all other regimes. At lower-frequencies, some regimes $(2,3,5,7$, and 8) present interdecadal variability.

\section{b. Associations with southern African rainfall}

Given the periodicity in the seasonal occurrence of most 20CR regimes peaks at least for one of the three dominant time scales of SA rainfall, we examine here the seasonal covariability between the SRI and regime occurrence. Figure 4 shows the corresponding FFT bandpassed time series for the interannual, QDV, and IDV time scales, together with the $f$ ratio and the contribution of each time scale to the total variance of each regime (see Fig. 1b for the SRI). All regimes mostly vary at the interannual time scale, which explains $65 \%-82 \%$ of their total variance compared to $4 \%-9 \%$ for QDV and $3 \%-7 \%$ for IDV. This hierarchy is consistent with what is observed for rainfall (D16; Fig. 1b), suggesting that each regime is useful for inferring various aspects of rainfall variability. However, fluctuations are generally less reproducible among the members at the interannual than the QDV/IDV time scales, which is intuitive given the reduced degrees of freedom for the lower frequencies. This is especially so for regimes 2 and 3 (7 and 8), for which the largest reproducibility is found for QDV 
Interannual

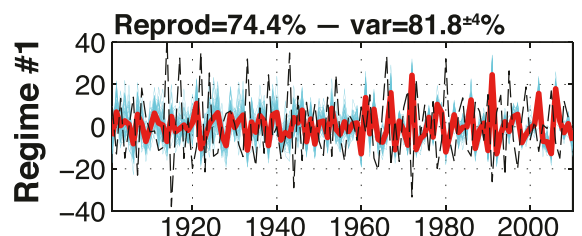

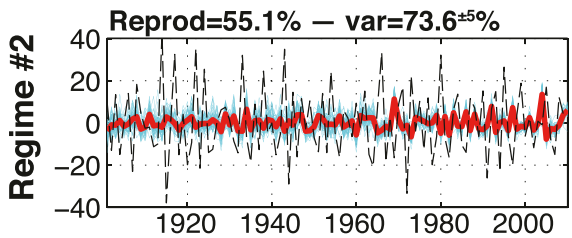

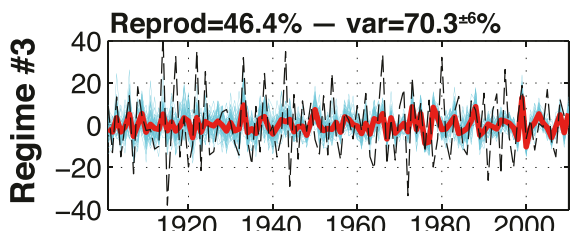

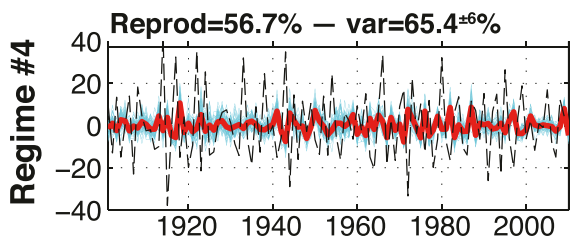
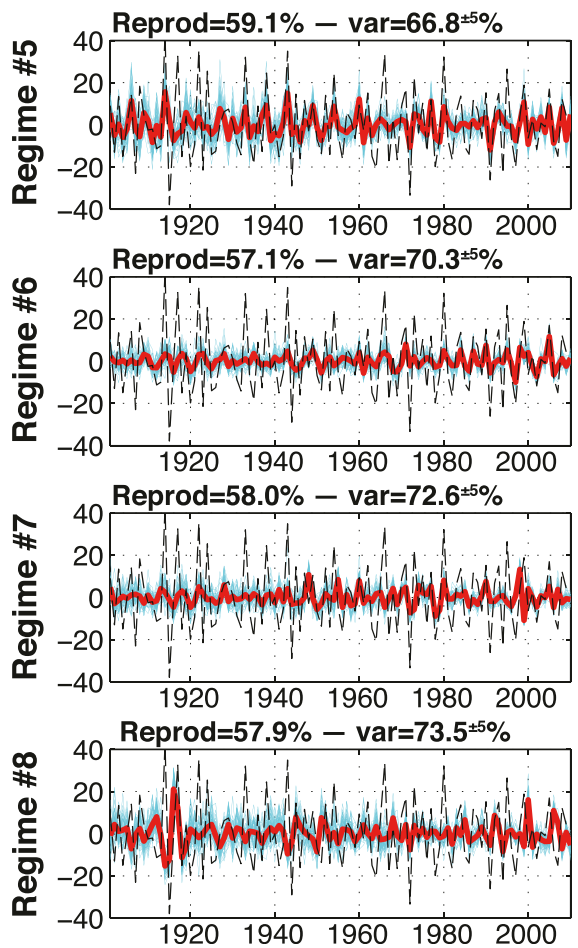

QDV

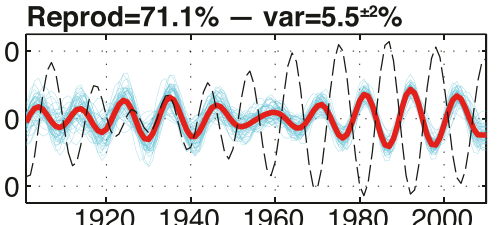

Reprod $=65.0 \%-$ var $=7.8^{ \pm 3} \%$

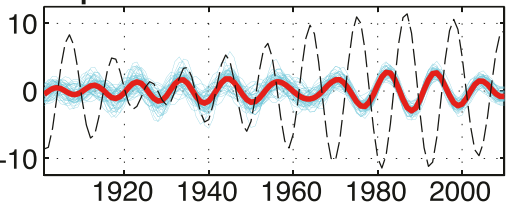

Reprod $=59.7 \%-$ var $=8.8 \pm 3 \%$

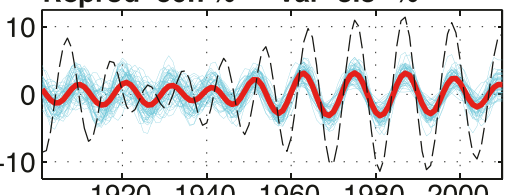

$19201940 \quad 1960 \quad 1980 \quad 2000$

Reprod $=71.7 \%-$ var $=8.3^{ \pm 3} \%$

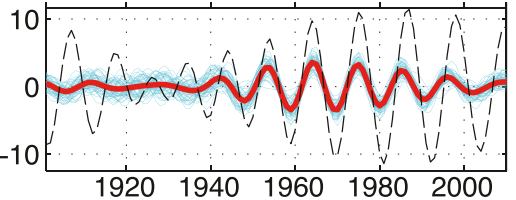

Reprod $=61.5 \%-\operatorname{var}=5.4^{ \pm 3} \%$

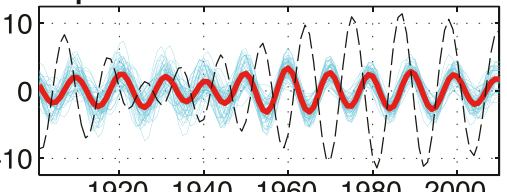

$\begin{array}{lllll}1920 & 1940 & 1960 & 1980 & 2000\end{array}$

Reprod $=43.8 \%-$ var $=5.0 \pm 3 \%$

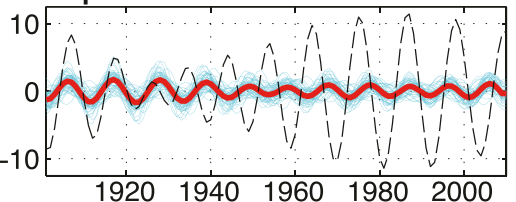

Reprod $=28.9 \%-$ var $=4.1 \pm 2 \%$

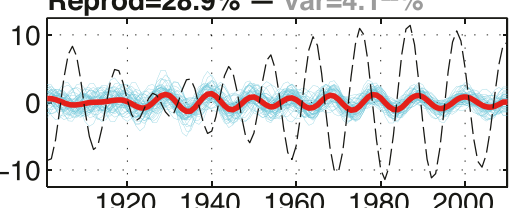

$1920 \quad 1940 \quad 1960 \quad 19802000$

Reprod $=\mathbf{5 2 . 6} \%-$ var $=5.1 \pm 2 \%$

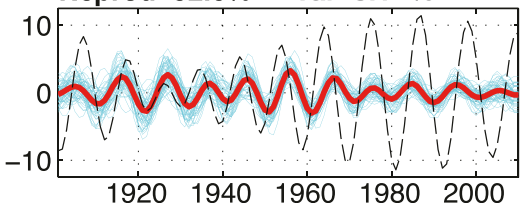

IDV

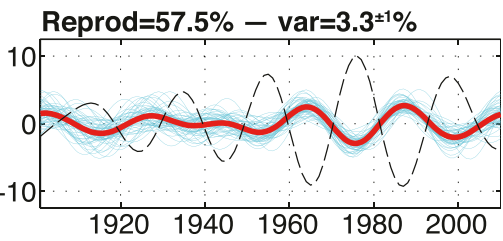

Reprod $=50.8 \%-$ var $=4.2 \pm 2 \%$

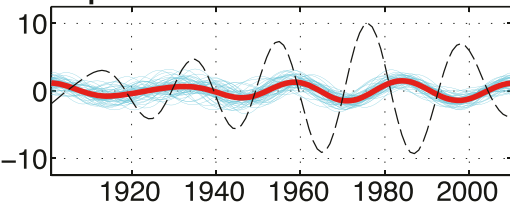

Reprod $=57.7 \%-$ var $=4.8 \pm 2 \%$

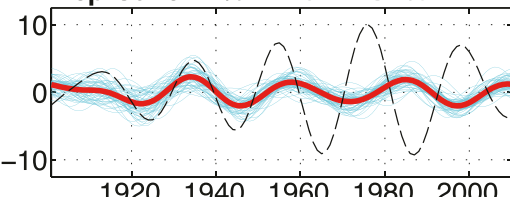

Reprod $=59.6 \%-$ var $=4.0 \pm 2 \%$

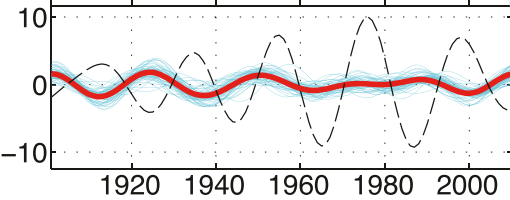

Reprod $=57.2 \%-$ var $=3.1 \pm 2 \%$

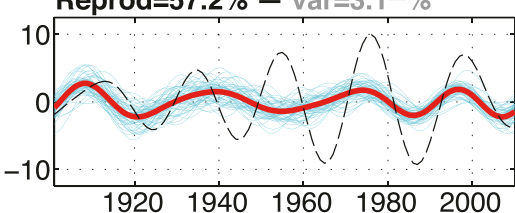

Reprod $=45.4 \%-$ var $=2.6^{ \pm 2} \%$

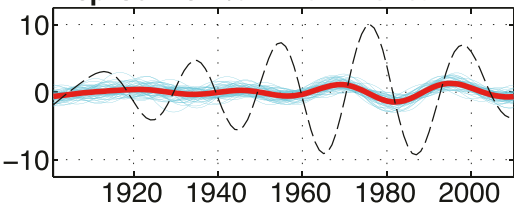

Reprod $=75.6 \%-$ var $=7.2^{ \pm 3} \%$

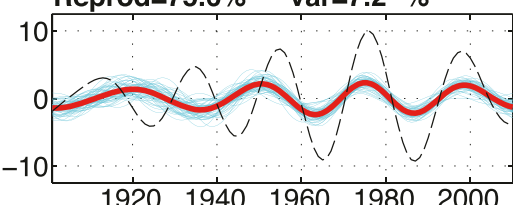

Reprod $=63.0 \%-\operatorname{var}=5.6 \pm 2 \%$

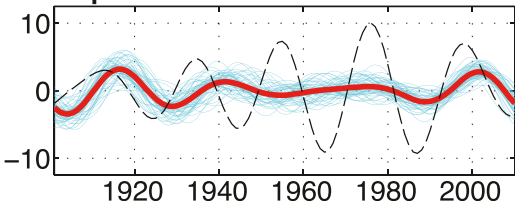

FIG. 4. As in Fig. 3b, but for reconstruction by FFT bandpass filter of Int., QDV, and IDV time scales of variability in each convective regime. Black dashed curves represent the corresponding filtered SRI time series. The fraction of reproducible variability and the fraction of total variance are labeled in the figure for each regime. Gray text denotes frequencies that are not significant at the $95 \%$ confidence level according to 1000 Monte-Carlo simulations of the red-noise spectra that consider the first-order autocorrelation of each convective regime and each individual ensemble member. 

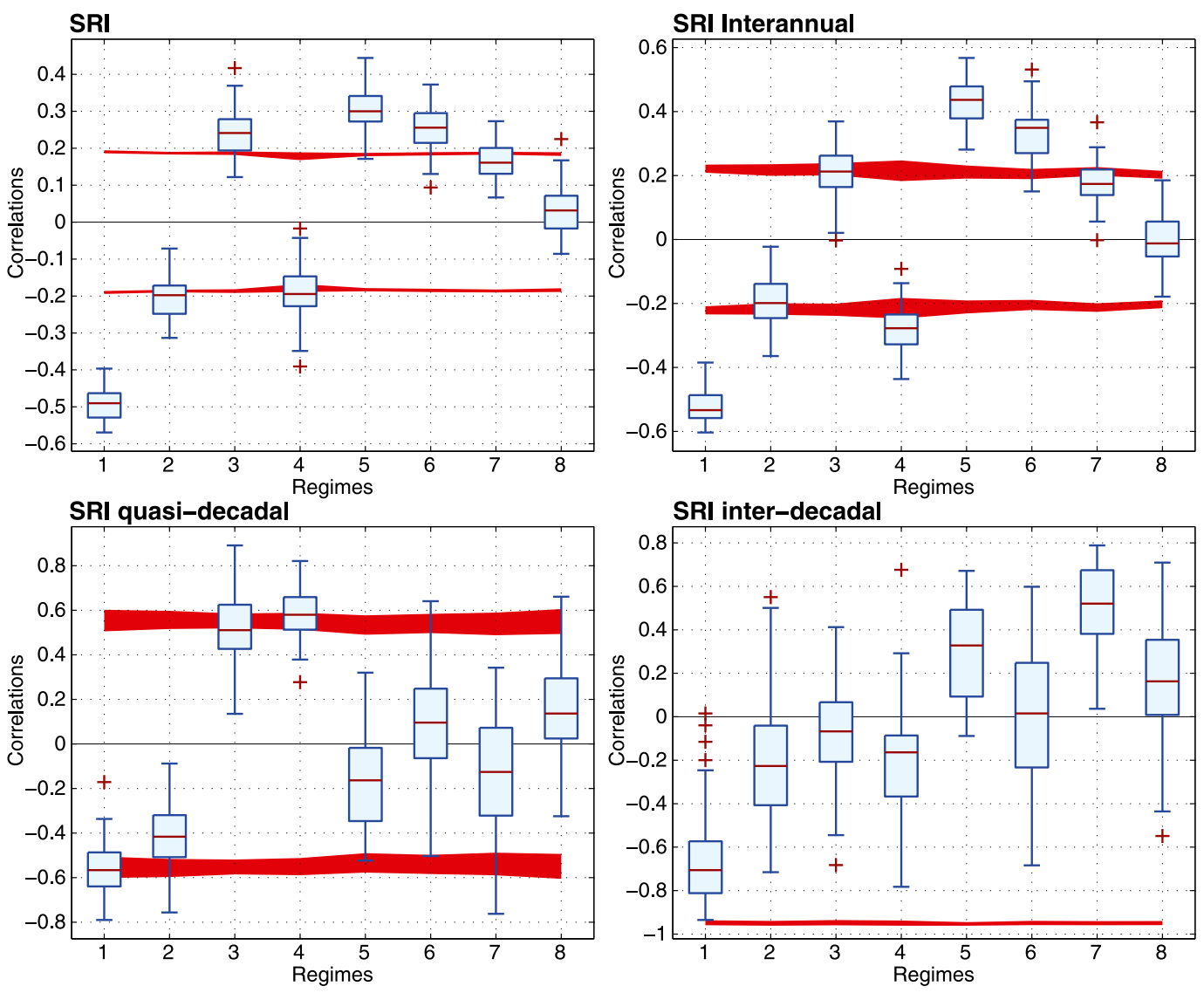

FIG. 5. Box-and-whisker plots of the correlations between the raw and filtered SRI (shown in Fig. 1a) and the corresponding raw and filtered regime occurrences (shown in Figs. $3 \mathrm{~b}$ and 4 ) for the 56 ensemble members of 20CR, for each time scale, period 1901-2011. The boxes have lines at the lower quartile, median, and upper-quartile values of the corresponding 56 correlation values. The whiskers are lines extending from each end of the box to show the range of the data. Outliers (outside of the 1.5 interquartile range) appear as plus signs. The red envelopes show the uncertainties in the $95 \%$ significance level according to a Monte-Carlo test that considers the time series autocorrelation.

(IDV). This strongly justifies the use of a multimember ensemble approach to account for such uncertainties.

Figure 5 displays the correlations between the raw/ filtered seasonal occurrence of the eight convective regimes and the raw/filtered SRI time series. Qualitatively similar results are obtained with rank and Pearson correlations, since the time series considered here are quasi-normal (not shown); this holds for all correlation analyses discussed below. The significance bounds substantially increase from interannual to IDV time scales because the degrees of freedom remain weak in our secular data [only 10 (5) full cycles for QDV (IDV); Fig. 4]. Hence, they are not relevant for assessing confidence in the correlations at the IDV and QDV time scales. This confidence is assessed by analyzing the spread within the 56 members using box-and-whisker plots in Fig. 5 and through the physics behind these correlations in section 4. Once again, the unfiltered and interannual relationships between convective regimes and rainfall are similar to one another since interannual variability accounts for most of their total variance (Figs. 1 and 4). More importantly, Fig. 5 underlines complex and regimedependent scale interactions.

The "clear sky" regimes 1 and 2 are negatively correlated to seasonal rainfall whatever the time scale, that is, increased occurrence associated with dry anomalies. There are additive effects between the three time scales for the post-1970s period (Fig. 4), but not before, because regimes 1 and 2 (i) do not fluctuate at the IDV time scale before the 1970s and (ii) covary in phase with rainfall at the QDV time scale from the 1920s to the 1950s. Regime 4 and rainfall also covary at the three time scales, but the relationship is slightly negative for interannual variability and IDV but strongly positive for QDV. Results are easier to interpret for the remaining regimes. Regime 3, which is associated with a westward 
shift in convection over subtropical SA, shows strong positive relationships with rainfall at both the interannual and QDV time scales (Fig. 5), with additive effects between them for most of the century (Fig. 4). Such century-long additive effects are also evident for two out of the three TTT regimes (5 and 7) that are positively correlated to rainfall at the interannual and IDV time scales. The third one (regime 6) is linked to rainfall at the interannual time scale only. Regime 8 , which documents the easternmost TTT, is logically not strongly correlated to the SRI.

By focusing on area-averaged rainfall, Fig. 5 limits the discussion of the spatial consistency in the rainfallregime relationship: this could conceal potential shifts in the location of large-scale convection induced by the three time scales. This issue is addressed by duplicating the analysis above using gridpoint rainfall over an extended SA domain. For brevity, Fig. 6 shows the results for the $20 \mathrm{CR}$ ensemble mean. Uncertainties are assessed in Fig. 7 by counting the number of members similar to the ensemble mean in terms of sign and statistical significance.

First, our gridpoint analysis demonstrates that the rainfall-regime relationship discussed in Fig. 5 represents well the entire region used to compute the SRI. This suggests limited artifact effects induced by the spatial averaging of rainfall. Second, the raw correlation patterns (Fig. 6) match rather well with the OLR patterns associated with each regime (Fig. 3a), except for some abrupt transitions between contrasted OLR anomalies like regimes 7 and 8 . This suggests some interference between daily rainfall and background climate conditions that modulate both the occurrence of these regimes and seasonal rainfall over SA. Third, striking similarities are found between the raw and interannual correlation patterns. This confirms that most of the contribution of large-scale synoptic convection to seasonal rainfall amounts occurs at the interannual time scale. Fourth, the ambiguous relationship between rainfall and regime 4 is confirmed, with strong negative (positive) correlations at the interannual (QDV) time scale and marked differences between unfiltered time series and interannual variability. Last, our gridpoint analysis complements findings shown in Fig. 5 by emphasizing some regional dependency in the rainfallregime relationship. The additive effects of the three time scales in the rainfall-regime 2 relationship (Fig. 5) is in fact highly regionally dependent, with dry (wet) conditions over subtropical (tropical) SA magnified at the QDV (IDV) time scale in most 20CR members (Figs. 6 and 7). The rainfall-regime 5 relationship is even more complex, with opposite effects of interannual and quasi-decadal variability in the tropics and additive effects of interannual and interdecadal variability in the subtropics.

\section{Understanding time-scale interactions}

Section 3 quantifies the scale interactions modulating both the seasonal occurrence of synoptic convective regimes and their relationship with rainfall. Here, we seek to understand the physics of such scale interactions by analyzing the climate background conditions associated with each time scale, their associations with the daily anomalies concomitant with the regimes, and the combined effects of low-frequency variability and shortterm synoptic perturbations on daily OLR and circulation anomalies.

\section{a. Climate background}

Following D16, a composite approach applied to global SST anomalies filtered within the three dominant time scales is used to identify the main modes of variability modulating the seasonal occurrence of convective regimes. For each time scale and 20CR ensemble member, composites are constructed as the difference between the NDJF seasons experiencing anomalously greater and lower occurrences of the eight convective regimes at the three different time scales. Figure 8 shows the median composites among the 56 ensemble members. The intermember uncertainties defined as the standard deviation of the 56 SST composites are systematically weak, so are not shown here.

At the interannual time scale, SST composite patterns associated with most regimes depict a strong influence of ENSO, as reflected by equatorial SST anomalies in the eastern Pacific, contrasting with anomalous horseshoe SST patterns of opposite signs farther west. El Niño conditions favor "clear sky" regimes 1 and 2, but also the ambiguous regime 4 promoting dry anomalies in subtropical SA. La Niña conditions favor continentally rooted TTTs (especially regimes 5 and 6). In addition to cold conditions in the central and eastern Pacific, regimes 7 and 8 are also related to significant SST anomalies in the SWIO region (Reason 1998; Reason and Mulenga 1999). This is also true, to a lesser extent, for regime 5 and is consistent with the dipolar SST anomalies in the SWIO described in Behera and Yamagata (2001).

At the QDV time scale (D16), decadal ENSO-like patterns describing a zonal dipole in SST anomalies along the equatorial Pacific and pronounced midlatitude SST anomalies in both hemispheres refer to the IPO (Di Lorenzo et al. 2015; Meehl et al. 2016). Regimes 1 and 2 (3 and 4) are associated with positive (negative) IPO anomalies, together with cold (warm) anomalies in the 

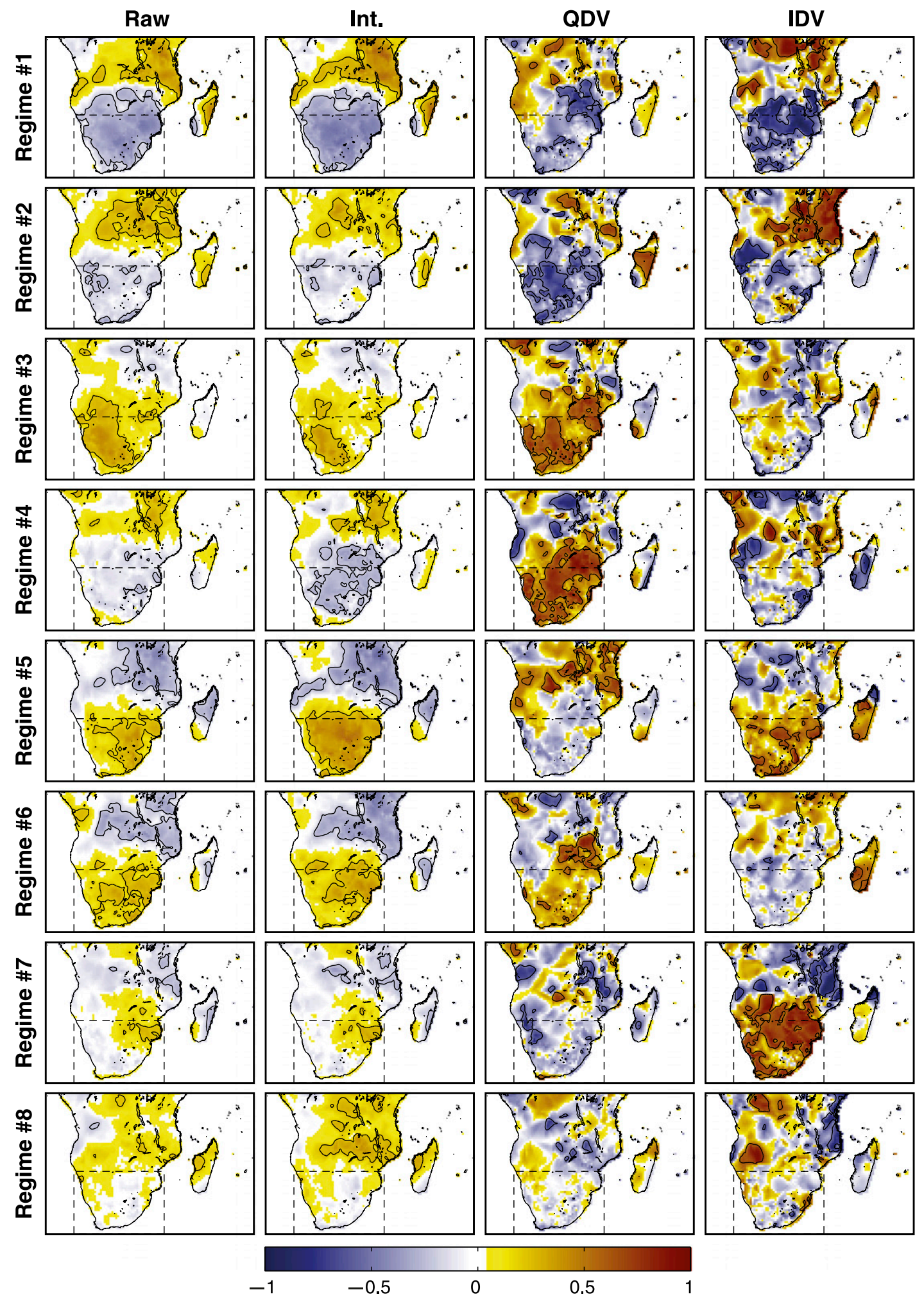

FIG. 6. Correlations between the number of seasonal occurrences of the eight convective regimes averaged over the 56 individual members of 20CR and austral summer (NDJF) seasonal rainfall amounts over SA, filtered at the same time scales. Black curves show correlations that are statistically significant at the $95 \%$ confidence level according to a Monte-Carlo test accounting for time series autocorrelation. 

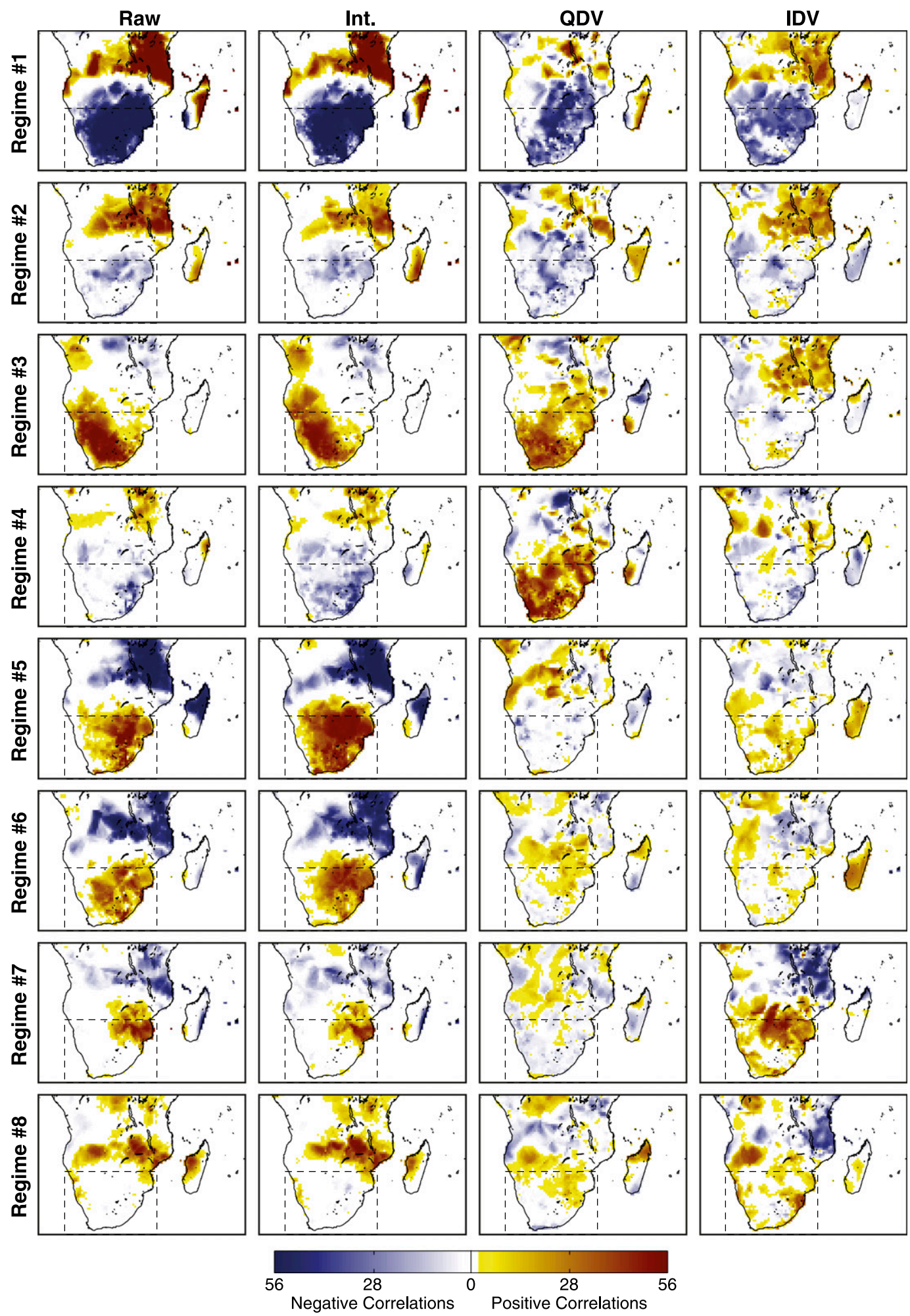

FIG. 7. Number of individual members of 20CR that show $95 \%$ significant positive (red) or negative (blue) correlations between the number of seasonal occurrences of the eight convective regimes and austral summer (NDJF) seasonal rainfall amounts over SA, filtered at the same time scales. 

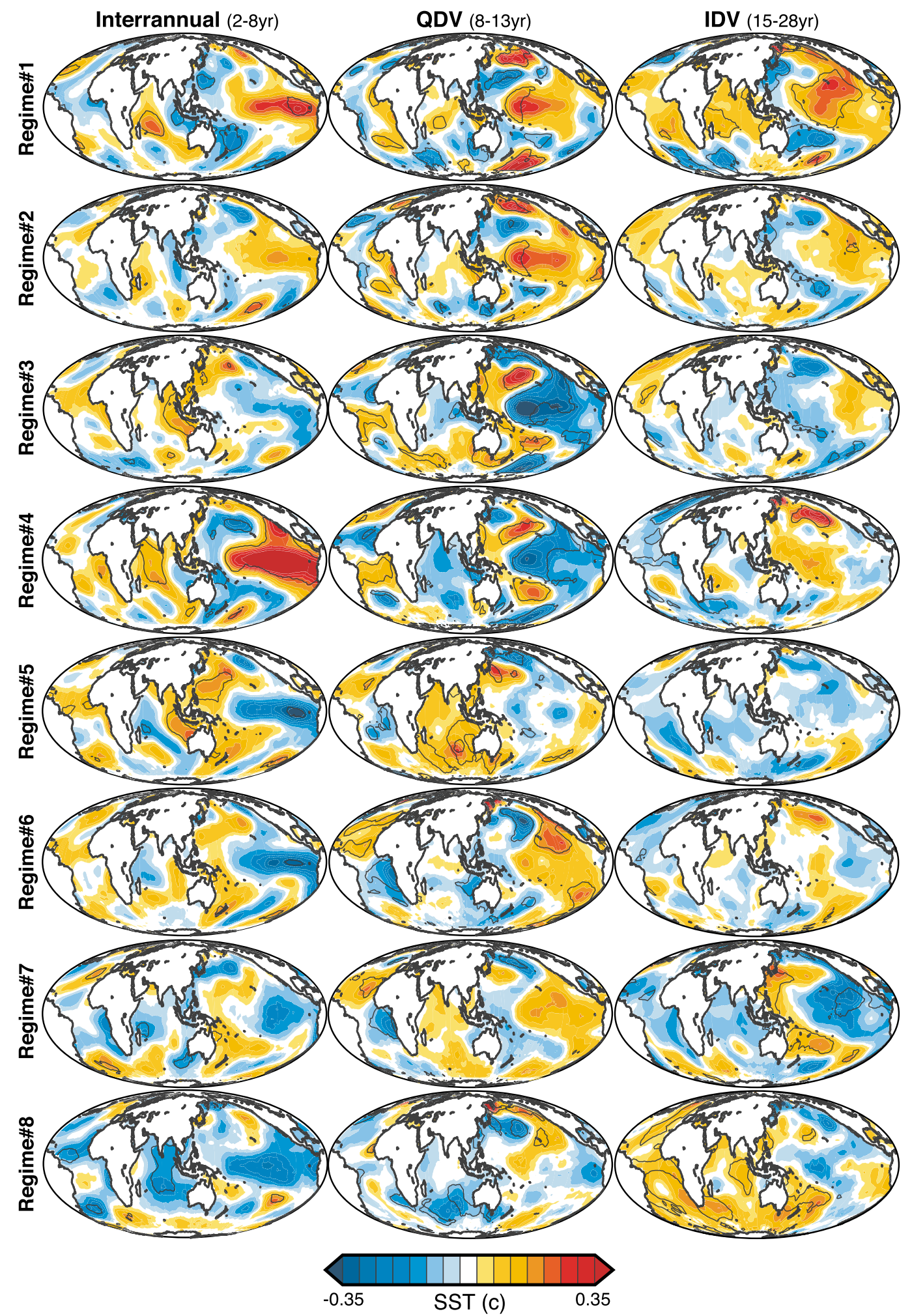

FIG. 8. Austral summer (NDJF) median SST anomalies associated with fluctuations in the occurrences of the eight convective regimes from the 20CR at the (left) Int. (2-8 years), (center) QDV (8-13 years), and (right) IDV (15-28 years) time scales. The median SST anomalies are determined using all individual ensemble members. The statistical significance (black contours) is estimated by testing the difference in means between SST anomalies, when anomalies in the NDJF occurrences of the eight convective regimes are positive and negative, through a modified $t$ test accounting for serial correlation in the time series at the $95 \%$ confidence level. 
tropical Indian Ocean and dipolar SST anomalies in the subtropical South Atlantic Ocean (Fig. 8). In contrast, the largest SST anomalies are not found in the equatorial Pacific for regimes 5-8, but are shifted poleward (Fig. 8). This may describe a predominant influence of regional climate fluctuations during the growing/decaying phases of the IPO, which require coherent and symmetrical signals between the North and South Pacific (Mantua et al. 1997; Di Lorenzo et al. 2015). However, nonmature IPO patterns are difficult to disentangle from the PDO, as hemispheric symmetry cannot be optimally assessed. These two modes of Pacific SST variability are likely to coexist and covary at the same time scale (Deser et al. 2004). This is even very likely when investigating their respective variability using 6-10-yr low-pass filters (e.g., Mantua et al. 1997; Deser et al. 2004; Parker et al. 2007; Dong and Dai 2015; Henley et al. 2015). Moreover, according to Newman et al. (2016), the difference between the IPO and PDO should primarily result from internal processes in the North Pacific, related to atmospheric noise a fortiori not occurring at specific times and scales. In addition to SST changes in the Pacific, more regional signals are obtained in the southern Atlantic.

At the IDV time scale, the PDO pattern is characterized by larger SST anomalies in the North than equatorial Pacific (Deser et al. 2004; Newman et al. 2016), with mature positive (negative) PDO anomalies for regimes 1 and 2 (7). SST signals associated with all other regimes are barely or not significant.

Figure 8 evidences scale interactions similar, from a statistical point of view, to those discussed in Figs. 5 and 6 . The two driest regimes ( 1 and, to a lesser extent, 2 ) are favored by warm conditions in the central or eastern equatorial Pacific and western Indian Ocean regardless of the time scale considered. Opposite SST anomalies prevail for wet regimes that show additive effects between the interannual and QDV (IDV) time scales [regime 3 (5-7)]. Conversely, and corroborating previous work (e.g., Allan et al. 2003), regimes with ambiguous influences on SA rainfall are associated with contrasted SST anomalies from one time scale to another. Yet, even for these regimes, cold (warm) SST anomalies in the eastern/central Pacific are favorable to abnormally dry (wet) conditions in SA. This is particularly exacerbated in regime 4 , for which very strong El Niño anomalies favor dryness at the interannual time scale, while negative IPO promotes more abundant seasonal rainfall at the quasi-decadal scale (Figs. 5, 6, and 8). As discussed in F09 for regional ENSO effects, these results could explain some of the nonlinear relationships between SA rainfall and decadal modes of climate variability, the opposite phases of these modes being associated with different types of rainfall responses in SA.

\section{b. Impact of low-frequency variability on seasonal and daily convection}

Previous sections analyzed to what extent modifications in the regime occurrence can be a key to understand rainfall variability over SA at the interannual, QDV, and IDV time scales. We attempt now to document potential changes in the intrinsic properties of the regimes linked to these climate fluctuations. In other words, independently of its occurrence, is a given regime associated with similar convective and atmospheric circulation anomalies regardless of the state of ENSO, IPO, and PDO? To properly address this question, we need to disentangle the specific effects of these fluctuations found in SA rainfall at low frequencies and the way these effects are combined with the short-lived anomalies associated with the regimes.

Figure 9 shows OLR anomalies during the opposite phases of the SRI (cf. Fig. 1a) at the three dominant time scales. Both filtered and raw seasonal OLR data are considered in the composite analyses to disentangle the specific influence of each time scale and scale additivity or antagonism with other ranges of climate variability.

At the raw and interannual time scales, the main seasonal OLR signal demonstrates the well-known longitudinal shift in the SICZ associated with the opposite states of ENSO (e.g., Cook 2001). The anomaly patterns for these time scales fit the OLR signature of ENSO over the region very well (F09; Pohl et al. 2009; Dieppois et al. 2015; D16). Such a zonal shift in the SICZ is much less evident at both the QDV and IDV time scales, and the OLR anomalies associated with the positive and negative phases of the SRI tend to be larger for unfiltered than for filtered OLR. This suggests strong interferences between these low-frequency modes of variability and the interannual time scale. For all ranges of variability, the regions with the largest OLR differences are also those in which the variability is the most robust (all of the 56 ensemble members reproducing qualitatively similar OLR differences between the opposite phases of the SRI; not shown). The main uncertainties are in the periphery of these regions, where the OLR anomalies change signs, denoting a stronger irreproducible component in the shape and extension of the anomaly patterns.

Figure 10 extends the results to the eight convective regimes by presenting the composite OLR anomalies during the regime occurrences under neutral rainy conditions, but also during the extreme rainy years identified in Fig. 1. Here, the interannual time scale is chosen as an example, since it concentrates the largest 


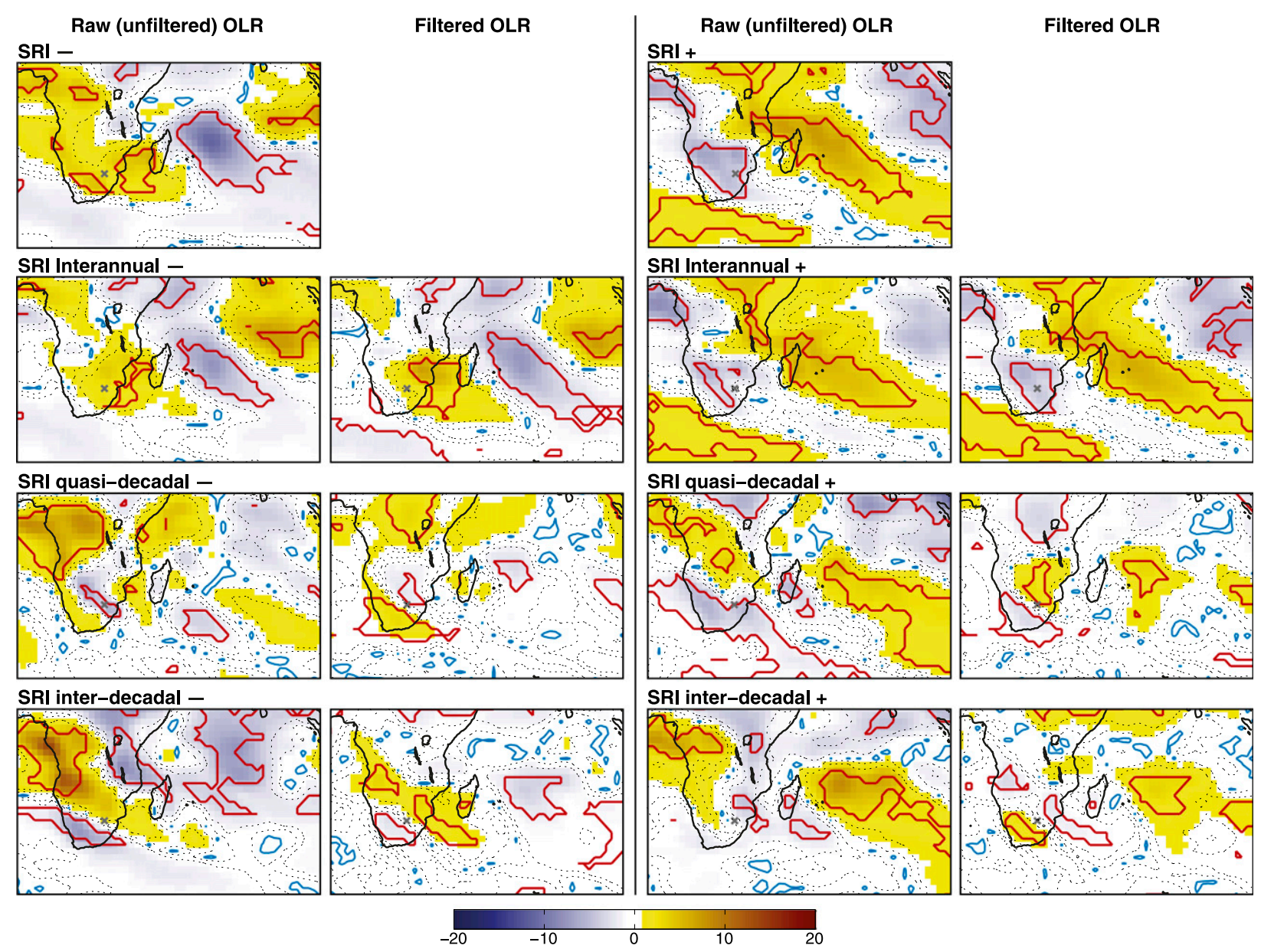

FIG. 9. Seasonal-mean OLR anomalies $\left(\mathrm{W} \mathrm{m}^{-2}\right.$ ) during the (left) negative and (right) positive phases of the raw and filtered SRI indices (shown in Fig. 1a) in the multimember average of 20CR, period 1901-2011. Only anomalies that are significant at the 95\% significance level according to a $t$ test are displayed. The number of individual members in agreement with the ensemble mean (same sign and same statistical significance) is shown by the black contours: less than 30 members (dashed contours), from 40 to 50 members (thin black contours) and 56 members (thick black contours).

variance, but qualitatively similar results are found for the QDV and IDV scales (not shown).

At the daily time scale, the specific anomalies associated, on the one hand, with the regimes, and, on the other hand, with the low-frequency modes of variability, appear to be approximately additive. The synoptic centers of action discriminated by the regimes are clearly discernible for all phases of interannual variability, but they are superimposed to the OLR dipole anomaly because of the longitudinal shift of the SICZ and discussed in Fig. 9. Locally, the combination of both influences can significantly modulate OLR anomalies. An example is given for the Gauteng province and the surroundings of Johannesburg (black cross in Fig. 9). There, enhanced convection prevails during regimes 5 and 6 . For regime 5 , anomalies are spatially more coherent under neutral and positive SRI conditions but are weakened during the negative SRI phases. For regime 6 , in addition to changes in the shape of the enhanced convection region, marked magnitude differences in OLR anomalies also emerge locally of $-10 \mathrm{~W} \mathrm{~m}^{-2}$ under negative and neutral conditions and up to $-25 \mathrm{~W} \mathrm{~m}^{-2}$ during the positive phase of the interannual SRI. Table 2 further quantifies the stability of the regimes, through field correlations between the average anomaly field associated with each regime on the one side, and similar anomaly fields associated with the opposite phases of the SRI at each time scale on the other side. Field correlations are often above 0.8 , hereby denoting strong similarities. The quasi-decadal time scale seems to concentrate the weakest changes in the regimeaverage properties. On the other hand, noticeable exceptions $(r<0.5)$ concern the association between regime 1 and the negative phase of the raw SRI, as well as regime 5 and the positive SRI at the interdecadal scale. 

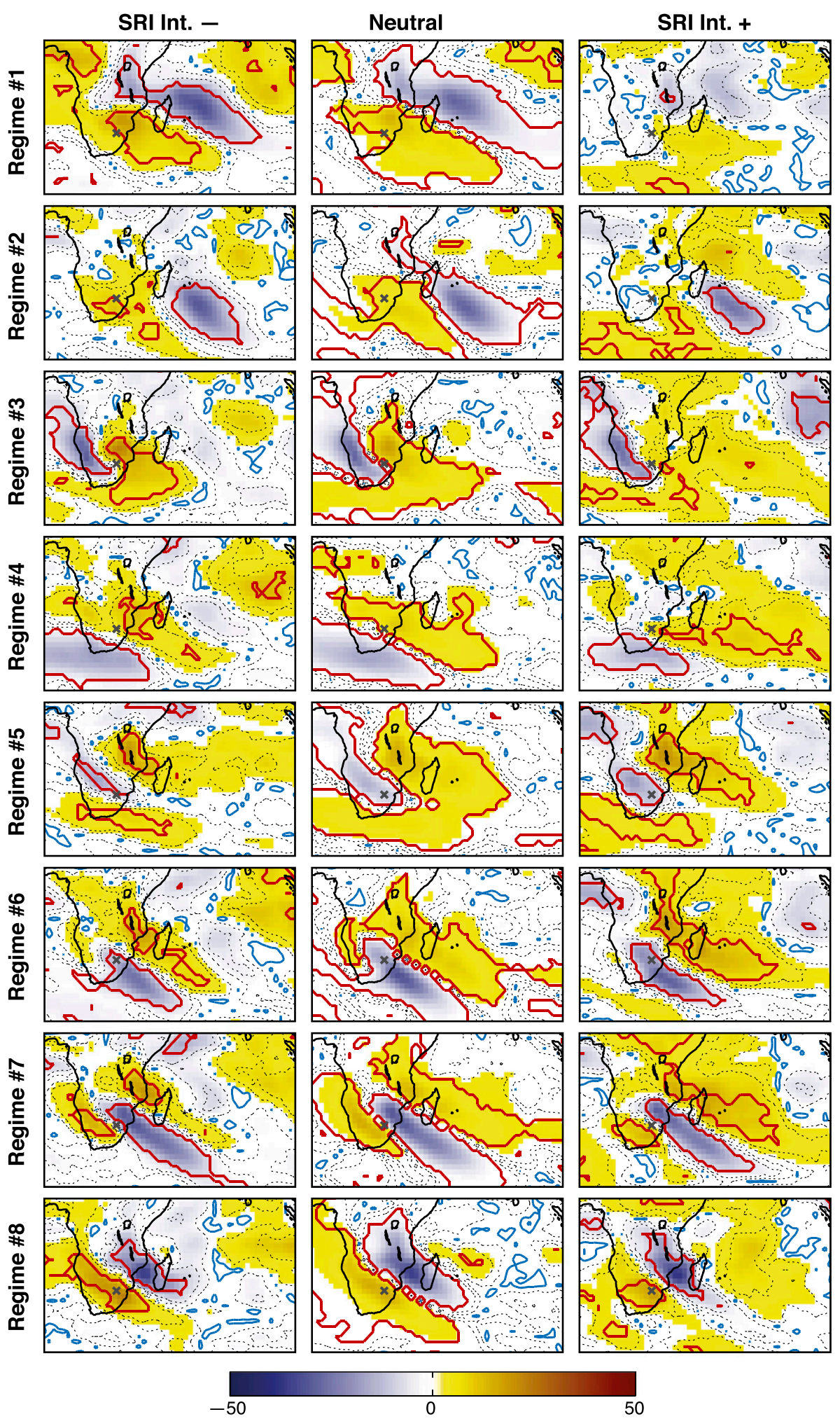

FIG. 10. Daily OLR anomalies $\left(\mathrm{W} \mathrm{m}^{-2}\right)$ during the occurrences of the eight convective regimes during the (left) negative, (central) neutral, and (right) positive phases of the SRI index filtered at the interannual time scale (shown in Fig. 1a) according to the multimember ensemble mean of 20CR. Only anomalies that are significant at the $95 \%$ significance level according to a $t$ test are displayed. The blue cross shows the Gauteng province of South Africa discussed in the text. 
TABLE 2. Field correlation between the OLR anomalies associated with each regime over the whole 1901-2011 period, as shown in Fig. 3a, and those during the opposite phases (below the 10th and above the 90th percentile values) of the seasonal raw and filtered SRI at each time scale. Correlations above 0.9 are in bold, and those below 0.5 are in italics. Statistical field significance [taking into account the false discovery rate as in Benjamini and Yekutieli (2001)] is estimated at $r=0.37$.

\begin{tabular}{lccccccccc}
\hline \hline & & Regime 1 & Regime 2 & Regime 3 & Regime 4 & Regime 5 & Regime 6 & Regime 7 & Regime 8 \\
\hline Raw & $\mathbf{-}$ & 0.49 & 0.72 & 0.81 & 0.76 & $\mathbf{0 . 9 1}$ & 0.86 & $\mathbf{0 . 9 0}$ & $\mathbf{0 . 9 0}$ \\
& + & 0.89 & 0.88 & 0.78 & 0.78 & 0.70 & 0.74 & 0.85 & 0.81 \\
Int. & - & 0.64 & 0.73 & 0.74 & 0.69 & $\mathbf{0 . 9 2}$ & 0.82 & 0.88 & 0.84 \\
& + & $\mathbf{0 . 9 2}$ & 0.87 & 0.82 & 0.71 & 0.73 & 0.73 & 0.82 & 0.86 \\
QDV & - & 0.87 & 0.85 & 0.88 & 0.87 & 0.80 & $\mathbf{0 . 9 0}$ & $\mathbf{0 . 9 1}$ & $\mathbf{0 . 9 1}$ \\
& + & 0.86 & $\mathbf{0 . 9 2}$ & 0.77 & 0.79 & 0.80 & $\mathbf{0 . 9 1}$ & $\mathbf{0 . 9 0}$ & $\mathbf{0 . 9 0}$ \\
IDV & $\mathbf{-}$ & 0.84 & 0.85 & 0.79 & 0.88 & 0.70 & 0.86 & $\mathbf{0 . 9 3}$ & $\mathbf{0 . 9 1}$ \\
& + & 0.89 & 0.85 & 0.75 & 0.81 & 0.40 & 0.75 & 0.77 & 0.88 \\
\hline
\end{tabular}

In spite of some modulations of the anomalies associated with the regimes, their intrinsic properties remain thus rather similar across low-frequency time scales.

\section{c. Atmospheric dynamics}

This section discusses how the atmospheric circulation over SA is modulated by the three dominant time scales investigated in this study. For data-availability reasons and conciseness, analyses focus on low-level wind anomalies and associated convergence and vorticity. Figure 11 presents the seasonal circulation anomalies associated with the positive phase of the raw (nonfiltered) and filtered (i.e., interannual, QDV, and IDV) SRI. Independently from the time scale considered, low-level anticyclonic anomalies prevail in the southwestern Indian Ocean during the positive phase of the SRI. The persistence of this pattern across the scales confirms the critical role of the Mascarene high for modulating SA rainfall through favoring moisture flux transport from the Indian Ocean to SA landmass. These anticyclonic anomalies, however, differ in both location and spatial extension across the scales. At the interannual time scale, they are located around Madagascar and promote low-level wind convergence in the eastern part
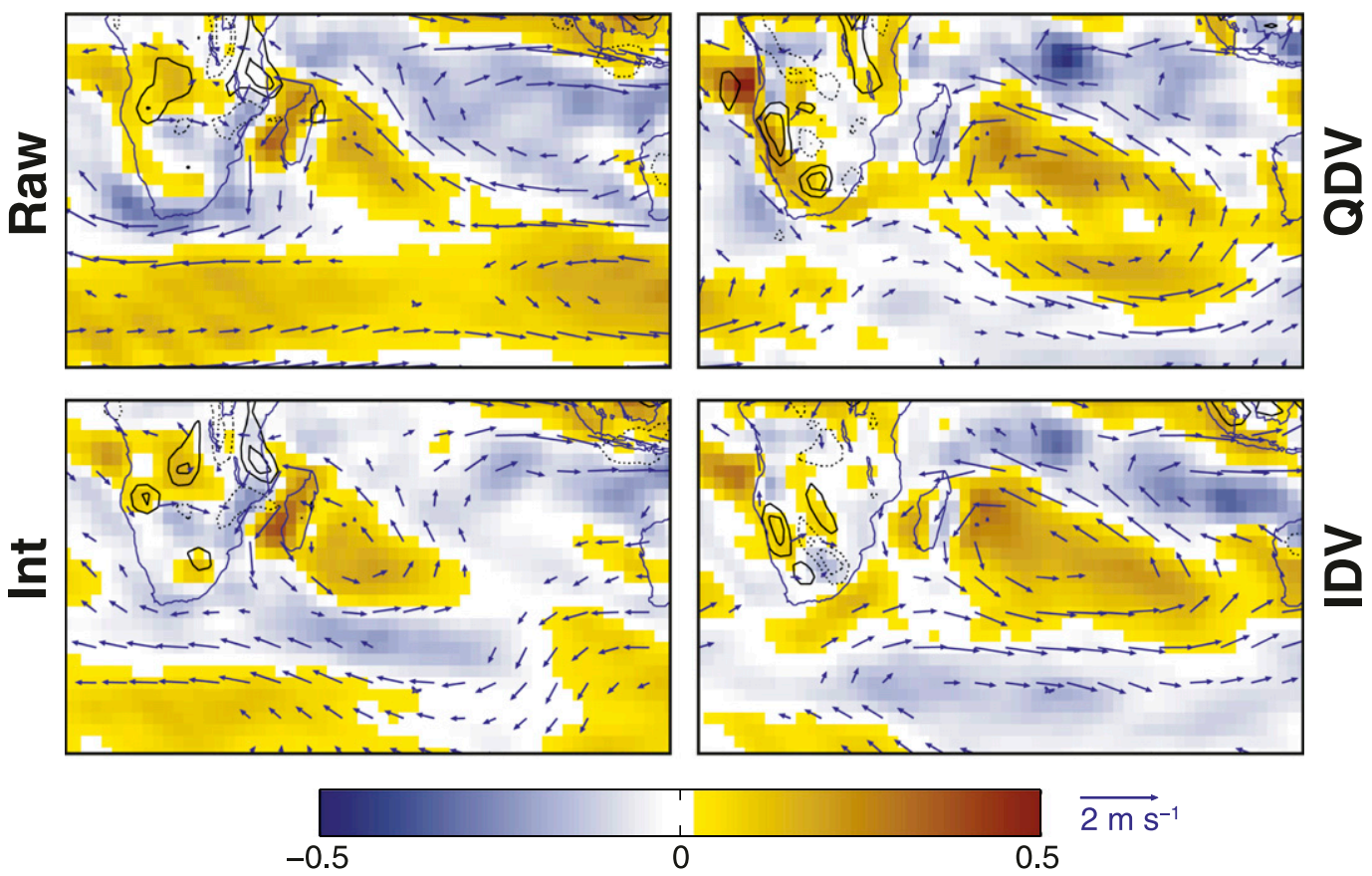

FIG. 11. As in Fig. 9, but for 850-hPa horizontal wind anomalies, during the positive phase of the raw and filtered SRI indices. Contours show associated divergence anomalies $\left(\mathrm{s}^{-1}\right)$ : solid (dotted) contours denote divergence (convergence) anomalies. Contour interval is every $5 \times 10^{-2} \mathrm{~s}^{-1}$, and the zero contour is omitted. Shadings show associated vorticity anomalies $\left(\mathrm{s}^{-1}\right)$. All analyses are based on 20CR ensemble mean. Only anomalies that are significant at the $95 \%$ significance level according to a $t$ test are displayed. 

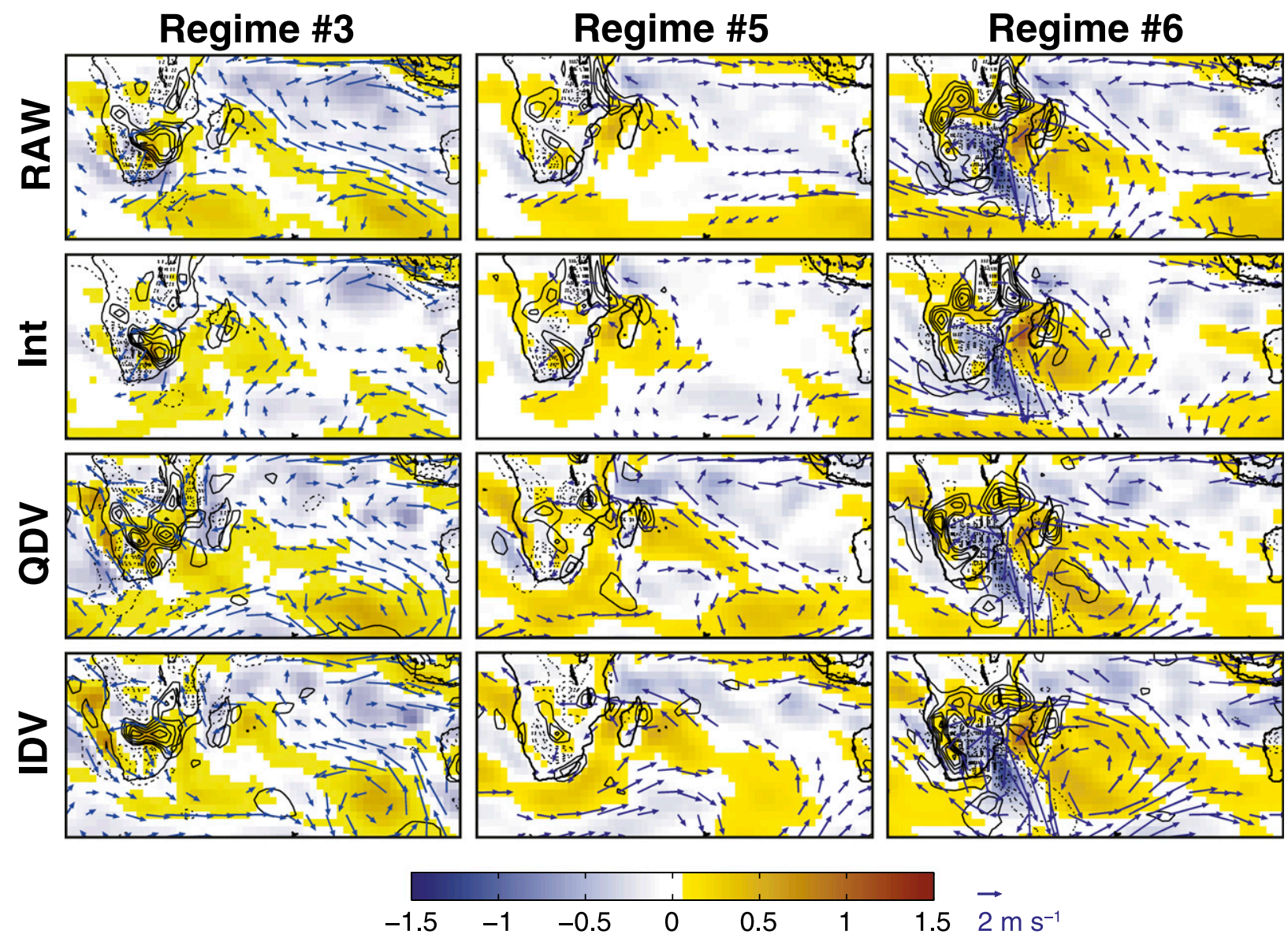

FIG. 12. As in Fig. 11, but during the occurrence of regimes 3, 5, and 6, chosen as examples.

of subtropical SA. This pattern is quite close to that found when considering the positive phase of the unfiltered SRI, highlighting once again the major contribution of interannual variability to the overall variability. The anticyclonic anomalies are shifted eastward and are of larger spatial extension at the QDV and IDV time scales and are reminiscent of the multidecadal shift in the south Indian Ocean anticyclone depicted by Allan et al. (1995). They embed almost the whole south Indian Ocean, east of Madagascar, but are located too far eastward to significantly impact low-level wind convergence over SA and probably moisture transport from the Indian Ocean to the continent. This could contribute to explain the weak contribution of QDV and IDV time scales on SA seasonal rainfall amounts (Fig. 1).

Figure 12 extends the above analysis to daily circulation anomalies associated with selected regimes during the positive phase of the SRI, both unfiltered and filtered at the three time scales. The three regimes selected for analysis $(3,5$, and 6$)$ promote wet anomalies over the western part, entire, and eastern part of subtropical SA, respectively (Fig. 6). They occur more frequently during the positive phase of the SRI (Table 3). To first order, the circulation anomalies associated with each regime are very similar during the positive phase of both the unfiltered and the filtered SRI, at all time scales. The stability of the circulation patterns across the time scales demonstrates that the spatial characteristics of the regimes are mostly controlled by the synoptic time scale, while low-frequency variability (i.e., interannual, QDV, and IDV) is of secondary importance. Among the three selected regimes, regime 6 (continental TTT) illustrates well this point. The $850-\mathrm{hPa}$ anomalous trough-ridge pattern is very similar in location and intensity across the scales, leading to significant low-level wind convergence over subtropical SA and low-level wind divergence farther north in the tropics (Fig. 12, right column).

These results suggest that the average spatial characteristics of the regimes are not drastically modified by the low-frequency modes, unlike their occurrence (Fig. 4; Table 3). Therefore, considering the frequency of occurrence of the regimes may be sufficient to assess scale interactions in the context of regional rainfall and convection. Yet, these changes in the regime frequencies 
TABLE 3. Relative frequency (\%) of the regimes over the whole 1901-2011 period (first line) and during the opposite phases (below the 10th and above the 90th percentile values) of the seasonal raw and filtered SRI at each time scale.

\begin{tabular}{lcrrrrrrrr}
\hline & & Regime 1 & Regime 2 & Regime 3 & Regime 4 & Regime 5 & Regime 6 & Regime 7 & Regime 8 \\
\hline ALL & & 12.2 & 10.3 & 11.6 & 10.3 & 18.0 & 11.6 & 12.0 \\
Raw & - & 20.8 & 12.6 & 10.3 & 11.7 & 12.6 & 9.5 & 10.8 \\
& + & 4.8 & 8.3 & 15.9 & 7.3 & 26.4 & 13.1 & 11.4 \\
Int. & - & 19.4 & 9.7 & 13.3 & 13.0 & 14.2 & 10.2 & 10.5 \\
& + & 8.4 & 8.8 & 13.1 & 8.0 & 24.8 & 11.8 & 12.6 \\
QDV & - & 9.6 & 12.6 & 9.6 & 10.1 & 18.4 & 13.0 & 12.6 \\
& + & 7.7 & 9.0 & 15.4 & 12.5 & 17.4 & 14.2 & 12.0 \\
IDV & - & 15.2 & 9.0 & 13.2 & 15.2 & 12.0 & 12.7 & 14.1 \\
& + & 8.3 & 9.2 & 13.0 & 14.2 & 17.1 & 10.5 & 14.8 \\
\end{tabular}

cannot explain the whole regional climate variability. Although it is certainly useful to first document the scale interactions between synoptic and low-frequency variability, the clustering approach needs to be completed by complementary methodologies like self-organizing maps or fuzzy classifications.

\section{Discussion and conclusions}

This study aimed to provide a unified view between, on the one hand, the recurrent large-scale "convective regimes" proposed by F09 that discriminate synoptic-scale variability around SA and, on the other hand, the lowfrequency fluctuations of summer rainfall identified in D16, consisting of three dominant time scales (i.e., interannual: 2-8 years; QDV: 8-13 years; IDV: 15-28 years).

To that end, eight convective (OLR based) regimes were identified at the daily time scale over the NDJF 1901-2011 period in the 56 individual ensemble members of the 20CR (Compo et al. 2011). These regimes allow us to quantify to what extent regional climate variability at the three dominant time scales relates to modifications either in the frequencies or intrinsic properties of a limited number of recurrent configurations.

The robustness of the results is assessed by comparing 20CR to observations for the overlapping period and by accounting for the intermember spread within the 20CR ensemble along the twentieth century. The recurrent convective regimes identified in this work fit rather well with the seven depicted in F09 using satellite measurements. These regimes exhibit significant periodicities, which are consistent with the three above-mentioned dominant time scales modulating SA rainfall (D16). This suggests that regime occurrence fluctuates at time scales relevant for rainfall analysis. Such variability is interpreted as a response of the regional climate (including rainfall and large scale convective activity) to three modes of near global-scale climate variability, which are respectively dominant at the interannual (for
ENSO), quasi-decadal (for the IPO), and interdecadal (for the PDO) time scales.

The next step consists of 1) assessing the extent to which the occurrence of the regimes is relevant in future analyses to help understand low-frequency rainfall fluctuations, and 2) deconstructing these time scales into daily descriptors of intraseasonal variability. While there is strong regime dependency, two salient results are shared by all regimes and all time scales:

(i) Their seasonal occurrence significantly varies at the three variability ranges mentioned above. Warm conditions in the eastern Pacific, and more generally in the tropical ocean basins, tend to drive abnormally dry conditions in SA: this is true both for seasonal rainfall amounts, as well as for daily regimes promoting dry anomalies in SA. Reverse but nonlinear results concern cold SST and wet seasonal conditions/increased frequency of regimes favoring active convection over SA. While the three time scales clearly favor the seasonal occurrence of the driest regime (regime 1) during their positive phase (and reversely during their negative phase), their effects are more complex for the remaining regimes (especially 4 and 7), with scale-dependent and asymmetric influences on seasonal rainfall amounts. These results corroborate and complement the literature on synoptic climate variability over SA (e.g., Hart et al. 2010; Ratna et al. 2013; Macron et al. 2014), and generalize the results of F09 on interannual variability at the QDV and IDV scales.

(ii) Short-lived daily disturbances in the regional climate associated with the regimes are systematically of larger amplitude than seasonal anomalies associated with the interannual, QDV and IDV time scales. Thus the atmospheric configurations associated with each regime are only weakly modified during the opposite phases of the low-frequency modes of climate variability: the changes concern 
(a)

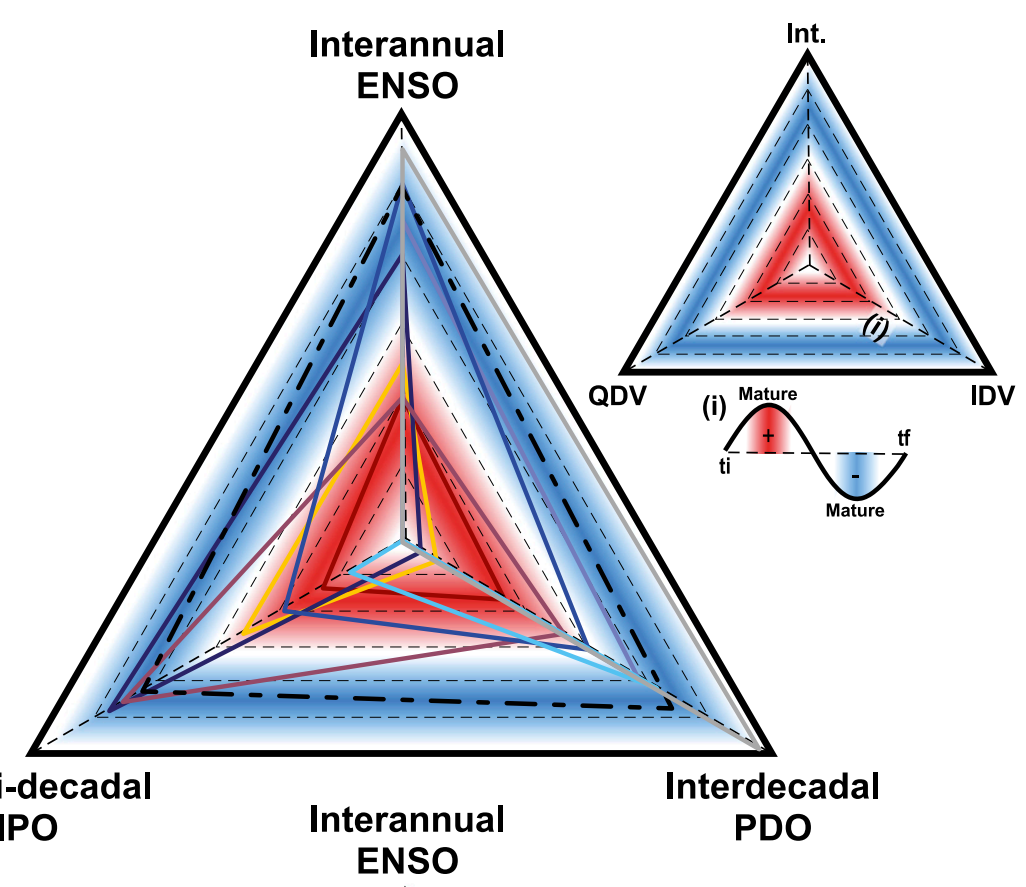

(b)

\section{Quasi-decadal IPO}

ENSO

\begin{tabular}{ll} 
Reg \#1 & Reg \#5 \\
Reg \#2 & Reg \#6 \\
Reg \#3 & Reg \#7 \\
Reg \#4 & Reg \#8 \\
- - - & SRI \\
\hline
\end{tabular}

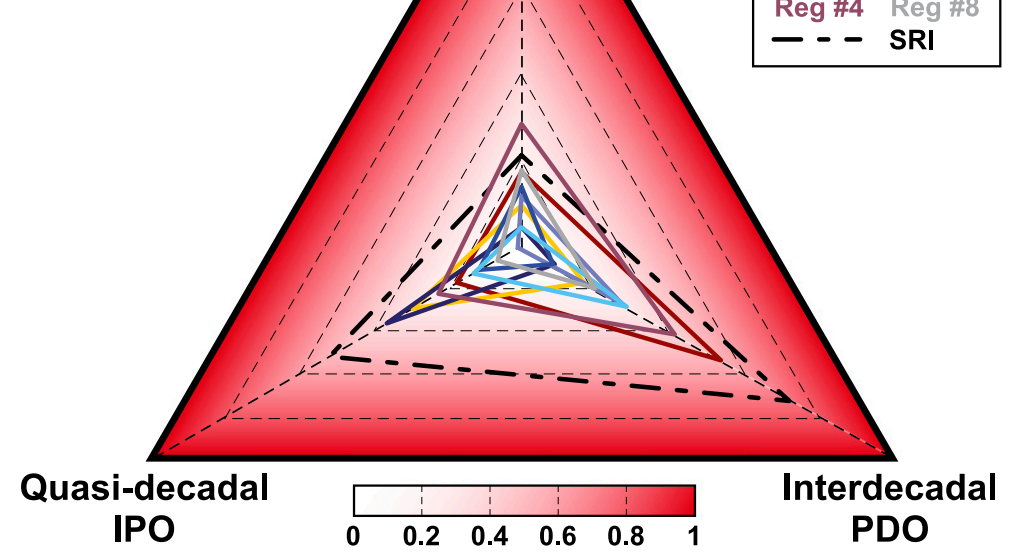

FIG. 13. (a) Spider chart showing the relationship between the median SST anomalies associated with enhanced Int. (2-8 years), QDV (8-13 years), and IDV (15-28 years) in the occurrence of each convective regime from the 20CR individual members and the maturation phases of ENSO, the IPO, and the PDO, respectively. Different maturation phases have been extracted using lagged composite analysis centered on periods of enhanced interannual and quasi-decadal SST variability in the equatorial Pacific $\left(20^{\circ} \mathrm{S}-20^{\circ} \mathrm{N}, 100^{\circ} \mathrm{E}-75^{\circ} \mathrm{W}\right)$ for ENSO and the IPO. Interdecadal SST variability in the North Pacific $\left(0^{\circ}-65^{\circ} \mathrm{N}, 100^{\circ} \mathrm{E}-100^{\circ} \mathrm{W}\right)$ is used to extract the maturation phases of the PDO. The maturation phases are displayed from the center to the apex of the triangle, as shown in the right-side legend: neutral, growing positive phase, mature positive phase (red shaded area); withdrawing positive phase, neutral, growing negative phase, maturate negative phase (blue shaded area); and withdrawing negative phase, neutral. Relationships between the maturation phases of the Pacific SST variability at the three time scales and the median composite SST anomalies associated with the eight convective regimes are determined using spatial correlation. Corresponding patterns associated with the eight convective regimes are displayed using different colors depending on their links with the SRI: very wet to moderate wet conditions (dark to light blue); two contrasted neutral conditions (purple and gray); and very dry to moderate dry conditions (red to orange). (b) As in (a), but for the absolute values of the linear correlations between the seasonal occurrences of each regime and the same filtered SST indices. Axes are from 0 to 1 , with a dashed line every 0.2 (see color legend). 
only the periphery, the shape, and/or the amplitude of the anomalies, rather than the location of the patterns. For instance, the dynamic component of synoptic-scale TTT systems is found to have a wider latitudinal envelope and to extend farther south under some favorable conditions identified at the quasi-decadal time scale; however, even though their occurrences can be changed, the existence and the general structure of these TTTs is barely affected. This implies that the regime occurrence alone can be considered as a good approximation to explain rainfall totals and climate variability over SA, both at the synoptic and low-frequency time scales.

The issue stressed by the second point above is particularly promising for seasonal forecasting and/or climate change projections. It suggests that the seasonal occurrence of the large-scale convective regime can be used as an efficient key to understand and characterize scale interactions in SA, while neglecting changes in their associated anomaly fields across time scales does not significantly alter the information. Thus, Fig. 13 summarizes both the phase (Fig. 13a) and the strength of the relationship (Fig. 13b) between the occurrence of each regime and each mode of interannual or quasi- or interdecadal variability. The SRI is also considered in the analysis. The strength of the statistical relationship (Fig. 13b) is assessed through linear correlation between the SRI and the regime frequency on the one side and filtered SST indices representative of the ENSO, IPO, and PDO modes in the Pacific on the other side.

The "clear sky/dry" regimes (1 and 2) tend to occur more frequently under warm conditions in the Pacific, while the reverse holds for "convectively active/wet" regimes (Fig. 13a). This is consistent with the SRI itself. More ambiguous, scale-dependent results are confirmed for regimes 4 and 6, while regime 8 shows weaker association with Pacific SST. As computed over more than a century, linear correlations are usually weaker for interannual than for QDV and IDV time scales, for which the number of degrees of freedom is much reduced. Yet, they illustrate the varying skill and relevance of each regime to infer the regional variability at the three time scales analyzed in this work (e.g., regimes 4, 3, and 1, peaking at the interannual, QDV, and IDV time scales, respectively). Given the temporal inertia of associated modes of variability, these phase relationships (Fig. 13a), combined with the intensity of the covariability with $\mathrm{Pa}$ cific SST (Fig. 13b), could prove to be useful seasonal predictors of SA rainfall and associated intraseasonal descriptors (such as the number of dry days).

One of the main limitations of the methodology used in this study involves the short-lived perturbations or phenomena that recurrently cause significant rainfall amounts over the region and are either too small or too rare to attract a convective regime. Mesoscale convective complexes (Blamey and Reason 2012) or cut-off lows (Favre et al. 2013) are among those and could thus not be analyzed in this work. Similarly, the occasional influence of either tropical or extratropical cyclones, or tropical lows, cannot be properly addressed here, although these phenomena have led to severe flooding events or substantial loss of life and damage over the region. This caveat needs to be addressed in future work, especially to assess the covariability of these small or rare features of the regional climate with other rainbearing systems (like TTTs) and modes of low-frequency variability (such as ENSO, IPO, and PDO). Another limitation concerns the internal variability of the regimes: even though their mean anomaly fields do not significantly change at the interannual and decadal scales, they can show substantial changes from one day (ascribed to a given regime) to another. This issue concerns all classification studies, which aim to discretize, into a limited number of recurrent configurations, a continuous phenomenon-namely, spatial and temporal climate variability.

By illustrating and ranking the importance of these low-frequency modes in modulating short-lived synoptic-scale variability, this work suggests that both largescale background and regional-scale information should be incorporated to improve (statistical, dynamical, or statistic-dynamical) subseasonal to seasonal predictions of rainfall and climate over SA. While the former are clearly related to well-known modes of near global-scale climate variability, the latter can be efficiently inferred by the recurrent convective regimes. Changes in the frequency of these regimes could also be a relevant key to analyze climate projections by the end of the century in the Coupled Model Intercomparison Projects.

Acknowledgments. Gil Compo is thanked for making 20CR data available and for helpful discussions. Calculations were performed using HPC resources from DNUM CCUB (Centre de Calcul de l'Université de Bourgogne). Three anonymous reviewers are thanked for helping to improve the paper.

\section{APPENDIX A}

\section{Acronyms}

Below are summarized the acronyms used in the text and their meaning.
20CR
COADS
Twentieth Century Reanalysis, version 2c Comprehensive Ocean-Atmosphere Data Set 

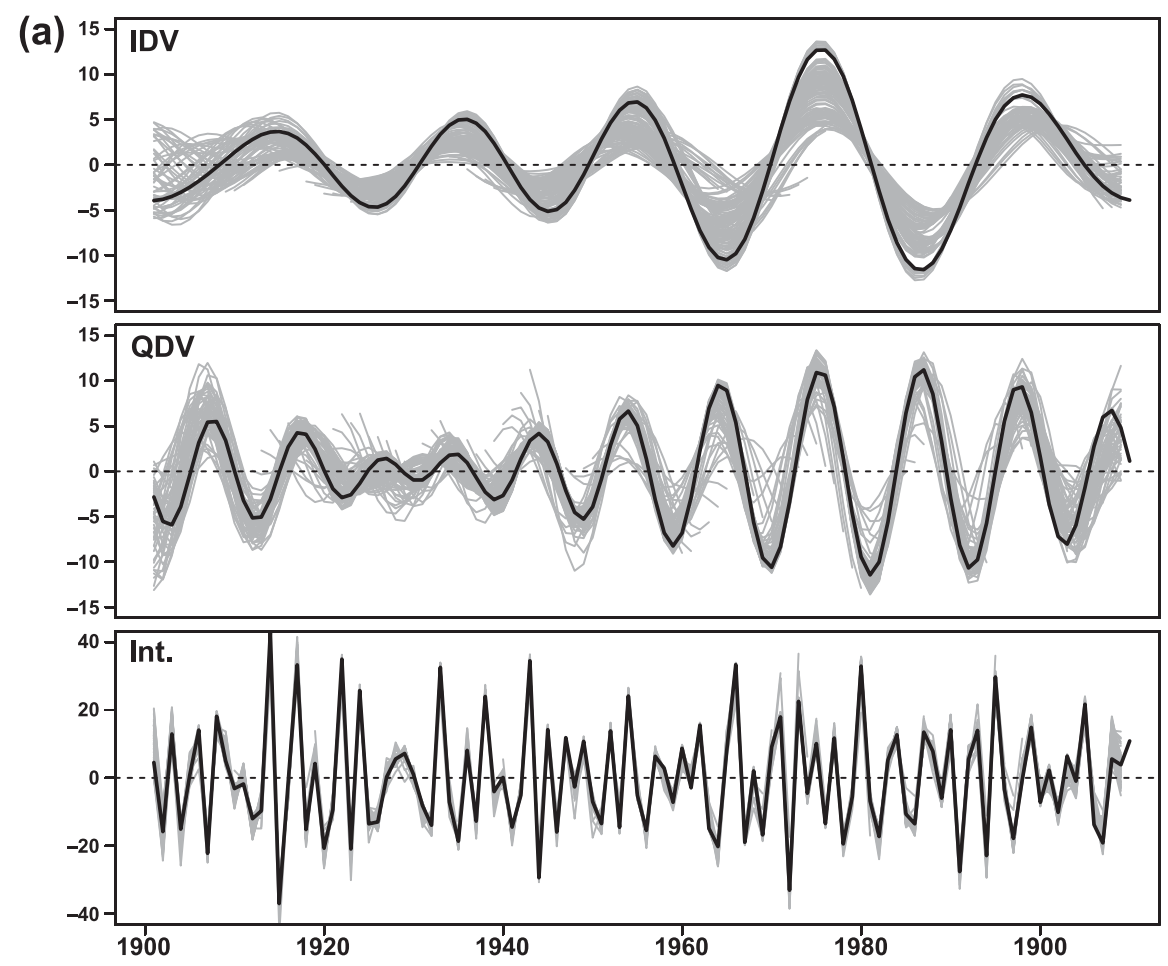

(b)
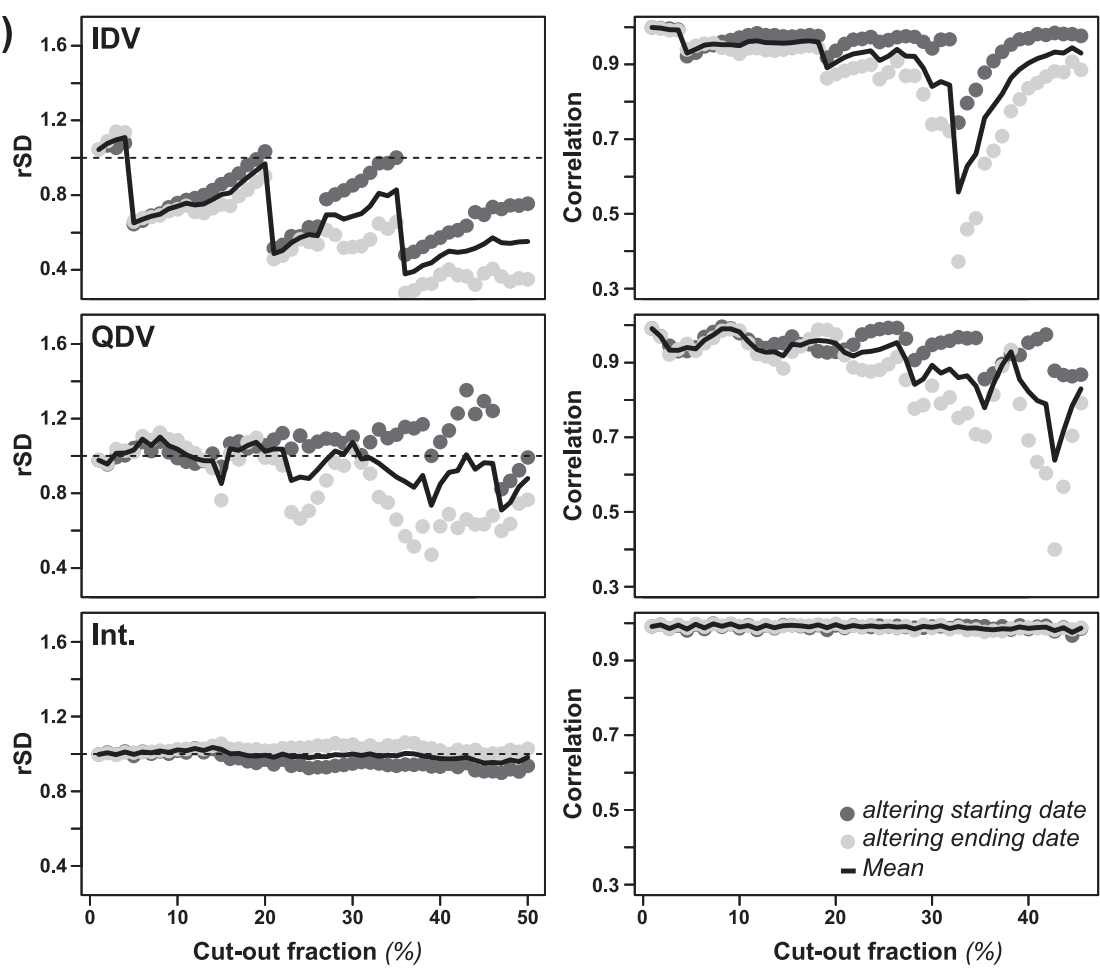

FIG. B1. Sensitivity to the sample size of FFT bandpass filtering. (a) Reconstruction by FFT bandpass filter of IDV, QDV, and Int. SRI variability using the whole time series (black lines) and those obtained after randomly modifying 50 times the starting and ending dates of the SRI (100 surrogate time series describing between $-1 \%$ and $-50 \%$ of the whole time series; gray lines). (b) FFT reconstruction skill assessment according to the (left) rSDs and the (right) correlation between FFT-based reconstructions using the whole time series and the 100 surrogate time series. Dark and light gray dotted lines indicate the scores resulting in changes of the starting and ending dates, respectively. Black lines are the mean score. 
CRU TS3.23 Climatic Research Unit dataset, version 3.23

D16 ENSO ERSST.v4 F09

IDV

IPO

MJO

NOAA

NCDC

OLR

PDO

QDV

SA

SAM

SICZ

SRI

SST

SWIO

TTT

Dieppois et al. (2016) reference

El Niño-Southern Oscillation

Extended Reconstructed SST

Fauchereau et al. (2009) reference

Interdecadal variability; $15-28$ years

Interdecadal Pacific oscillation

Madden-Julian oscillation

National Oceanic and Atmospheric Administration

National Climatic Data Center

Outgoing longwave radiation

Pacific decadal oscillation

Quasi-decadal variability; 8-13 years

Southern Africa

Southern annular mode

South Indian convergence zone

Summer rainfall index

Sea surface temperature

Southwest Indian Ocean

Tropical temperate trough

\section{APPENDIX B}

\section{Robustness of the Scale Decomposition to the Length of the Time Series}

The sensitivity to the filtering is assessed by extracting the three time scales through an FFT filter applied to 100 random samples with varying start or end dates (from \pm 1 to 50 years) extracted from the 1901-2014 period. Two metrics have been used to estimate the robustness: ratios of standard deviation (rSD) and correlations between FFT bandpass reconstructions using the entire time series and those obtained using the 100 surrogate time series. The uncertainty related to the sample size is negligible in terms of both the variance and timing of fluctuations (i.e., correlations) at the interannual time scale (Fig. B1b). It is also quite small at the quasi-decadal time scale, where the sample size has to be substantially reduced $(>\sim 25 \%)$ to impact both the variance and the timing of SA rainfall anomalies (Fig. B1b). Interestingly, the variance of IDV fluctuations is very sensitive to the sample size because of zero padding and both edge and wraparound effects (Fig. B1a). However, the timing of IDV rainfall anomalies is not as sensitive (Fig. B1b), hence ensuring that the main results discussed in the study are not dependent on the sample size.

\section{REFERENCES}

Allan, R. J., J. A. Lindesay, and C. J. C. Reason, 1995: Multidecadal variability in the climate system over the Indian Ocean region during the austral summer. J. Climate, 8, 1853-1873, https://doi.org/10.1175/1520-0442(1995)008<1853: MVITCS $>2.0 . C O ; 2$.

_ C. J. C. Reason, J. A. Lindesay, and T. J. Ansell, 2003: Protracted ENSO episodes and their impacts in the Indian Ocean region. Deep-Sea Res., 50, 2331-2347, https://doi.org/10.1016/ S0967-0645(03)00059-6.

Behera, S. K., and T. Yamagata, 2001: Subtropical SST dipole events in the southern Indian Ocean. Geophys. Res. Lett., 28 , 327-330, https://doi.org/10.1029/2000GL011451.

Benjamini, Y., and D. Yekutieli, 2001: The control of the false discovery rate in multiple testing under dependency. Ann. Stat., 29, 1165-1188, https://doi.org/10.1214/aos/1013699998.

Blamey, L. K., and Coauthors, 2015: Ecosystem change in the southern Benguela and the underlying processes. J. Mar. Syst., 144, 9-29, https://doi.org/10.1016/j.jmarsys.2014.11.006.

Blamey, R. C., and C. J. C. Reason, 2012: Mesoscale convective complexes over southern Africa. J. Climate, 25, 753-766, https://doi.org/10.1175/JCLI-D-10-05013.1.

$\longrightarrow$, and _- 2013: The role of mesoscale convective complexes in southern Africa summer rainfall. J. Climate, 26, 1654-1668, https://doi.org/10.1175/JCLI-D-12-00239.1.

Boulard, D., B. Pohl, J. Crétat, N. Vigaud, and T. Pham-Xuan, 2013: Downscaling large-scale climate variability using a regional climate model: The case of ENSO over southern Africa. Climate Dyn., 40, 1141-1168, https://doi.org/10.1007/ s00382-012-1400-6.

Cheng, X., and J. M. Wallace, 1993: Cluster analysis of the Northern Hemisphere wintertime 500-hPa height field: Spatial patterns. J. Atmos. Sci., 50, 2674-2696, https://doi.org/10.1175/ 1520-0469(1993)050<2674:CAOTNH >2.0.CO;2.

Compo, G. P., and Coauthors, 2011: The Twentieth Century Reanalysis Project. Quart. J. Roy. Meteor. Soc., 137, 1-28, https:// doi.org/10.1002/qj.776.

Cook, C., C. J. C. Reason, and B. C. Hewitson, 2004: Wet and dry spells within particularly wet and dry summers in the South African summer rainfall region. Climate Res., 26, 17-31, https://doi.org/10.3354/cr026017.

Cook, K. H., 2000: The South Indian convergence zone and interannual rainfall variability over southern Africa. J. Climate, 13, 3789-3804, https://doi.org/10.1175/1520-0442(2000)013<3789: TSICZA $>2.0 . \mathrm{CO} ; 2$.

_ 2001: A Southern Hemisphere wave response to ENSO with implications for southern Africa precipitation. J. Atmos. Sci., 58, 2146-2162, https://doi.org/10.1175/1520-0469(2001)058<2146: ASHWRT $>2.0 . \mathrm{CO} ; 2$.

Crétat, J., and B. Pohl, 2012: How physical parameterizations can modulate internal variability in a regional climate model. J. Atmos. Sci., 69, 714-724, https://doi.org/10.1175/ JAS-D-11-0109.1.

, C. Macron, B. Pohl, and Y. Richard, 2011: Quantifying internal variability in a regional climate model: A case study for southern Africa. Climate Dyn., 37, 1335-1356, https://doi.org/ 10.1007/s00382-011-1021-5.

, Y. Richard, B. Pohl, M. Rouault, C. J. C. Reason, and N. Fauchereau, 2012: Recurrent daily rainfall patterns over South Africa and associated dynamics during the core of the austral summer. Int. J. Climatol., 32, 261-273, https://doi.org/ $10.1002 /$ joc. 2266 . 
- B. Pohl, C. C. Smith, N. Vigaud, and Y. Richard, 2015: An original way to evaluate daily rainfall variability simulated by a regional climate model: The case of South African austral summer rainfall. Int. J. Climatol., 35, 2485-2502, https:// doi.org/10.1002/joc.4155.

Dai, A., 2013: The influence of the inter-decadal Pacific oscillation on US precipitation during 1923-2010. Climate Dyn., 41, 633646, https://doi.org/10.1007/s00382-012-1446-5.

Deser, C., A. S. Phillips, and J. W. Hurrell, 2004: Pacific interdecadal climate variability: Linkages between the tropics and the North Pacific during boreal winter since 1900. J. Climate, 17, 3109-3124, https://doi.org/10.1175/1520-0442(2004)017<3109: PICVLB $>2.0 . C O ; 2$.

Dieppois, B., M. Rouault, and M. New, 2015: The impact of ENSO on southern African rainfall in CMIP5 ocean atmosphere coupled climate models. Climate Dyn., 45, 2425-2442, https:// doi.org/10.1007/s00382-015-2480-x.

, B. Pohl, M. Rouault, M. New, D. Lawler, and N. Keenlyside, 2016: Interannual to interdecadal variability of winter and summer southern African rainfall, and their teleconnections. J. Geophys. Res. Atmos., 121, 6215-6239, https://doi.org/ 10.1002/2015JD024576.

Di Lorenzo, E., G. Liguori, N. Schneider, J. C. Furtado, B. T. Anderson, and M. A. Alexander, 2015: ENSO and meridional modes: A null hypothesis for Pacific climate variability. Geophys. Res. Lett., 42, 9440-9448, https://doi.org/10.1002/ 2015 GL066281.

Dong, B., and A. Dai, 2015: The influence of the interdecadal Pacific oscillation on temperature and precipitation over the globe. Climate Dyn., 45, 2667-2681, https://doi.org/10.1007/ s00382-015-2500-x.

Dyer, T. G. J., and P. D. Tyson, 1977: Estimating above and below normal rainfall periods over South Africa, 19722000. J. Appl. Meteor., 16, 145-147, https://doi.org/10.1175/ 1520-0450(1977)016<0145:EAABNR > 2.0.CO;2.

Dyson, L. L., and J. Van Heerden, 2001: The heavy rainfall and floods over the northeastern interior of South Africa during February 2000. S. Afr. J. Sci., 97, 80-86.

Engelbrecht, C. J., W. A. Landman, F. A. Engelbrecht, and J. Malherbe, 2015: A synoptic decomposition of rainfall over the cape south coast of South Africa. Climate Dyn., 44, 25892607, https://doi.org/10.1007/s00382-014-2230-5.

Fauchereau, N., B. Pohl, C. J. C. Reason, M. Rouault, and Y. Richard, 2009: Recurrent daily OLR patterns in the southern Africa/southwest Indian Ocean region, implications for South African rainfall and teleconnections. Climate Dyn., 32, 575-591, https://doi.org/10.1007/s00382-008-0426-2.

Favre, A., B. Hewitson, C. Lennard, R. Cerezo-Mota, and M. Tadross, 2013: Cut-off lows in the South Africa region and their contribution to precipitation. Climate Dyn., 41, 23312351, https://doi.org/10.1007/s00382-012-1579-6.

Fogt, R. L., and D. H. Bromwich, 2006: Decadal variability of the ENSO teleconnection to the high-latitude South Pacific governed by coupling with the southern annular mode. J. Climate, 19, 979-997, https://doi.org/10.1175/JCLI3671.1.

Hansingo, K., and C. J. C. Reason, 2009: Modelling the atmospheric response over southern Africa to SST forcing in the southeast tropical Atlantic and southwest subtropical Indian Oceans. Int. J. Climatol., 29, 1001-1012, https://doi.org/10.1002/joc.1919.

Harris, I., P. D. Jones, T. J. Osborn, and D. H. Lister, 2014: Updated high-resolution grids of monthly climatic observations-The CRU TS3.10 dataset. Int. J. Climatol., 34, 623-642, https:// doi.org/10.1002/joc.3711.
Hart, N. C. G., C. J. C. Reason, and N. Fauchereau, 2010: Tropicalextratropical interactions over southern Africa: Three cases of heavy summer season rainfall. Mon. Wea. Rev., 138, 26082623, https://doi.org/10.1175/2010MWR3070.1.

,$- \ldots$, and -2013 : Cloud bands over southern Africa: Seasonality, contribution to rainfall variability and modulation by the MJO. Climate Dyn., 41, 1199-1212, https://doi.org/ 10.1007/s00382-012-1589-4.

Henley, B. J., J. Gergis, D. J. Karoly, S. Power, J. Kennedy, and C. K. Folland, 2015: A tripole index for the interdecadal Pacific oscillation. Climate Dyn., 45, 3077-3090, https://doi.org/ 10.1007/s00382-015-2525-1.

Hermes, J. C., and C. J. C. Reason, 2009: Variability in sea-surface temperature and winds in the tropical south-east Atlantic Ocean and regional rainfall relationships. Int. J. Climatol., 29, 11-21, https://doi.org/10.1002/joc.1711.

Hoell, A., C. Funk, J. Zinke, and L. Harrison, 2017: Modulation of the southern Africa precipitation response to the El Niño Southern Oscillation by the subtropical Indian Ocean dipole. Climate Dyn., 48, 2529-2540, https://doi.org/10.1007/s00382016-3220-6.

Huang, B., and Coauthors, 2015: Extended reconstructed sea surface temperature version 4 (ERSST.v4). Part I: Upgrades and intercomparisons. J. Climate, 28, 911-930, https://doi.org/ 10.1175/JCLI-D-14-00006.1.

Jury, M. R., 2015: Factors contributing to a decadal oscillation in South African rainfall. Theor. Appl. Climatol., 120, 227-237, https://doi.org/10.1007/s00704-014-1165-4.

Kinter, J. L., M. J. Fennessy, V. Krishnamurthy, and L. Marx, 2004: An evaluation of the apparent interdecadal shift in the tropical divergent circulation in the NCEP-NCAR reanalysis. J. Climate, 17, 349-361, https://doi.org/10.1175/1520-0442(2004) 017<0349:AEOTAI>2.0.CO;2.

Kruger, A. C., 1999: The influence of the decadal-scale variability of summer rainfall on the impact of El-Niño and La Niña events in South Africa. Int. J. Climatol., 19, 5968, https://doi.org/10.1002/(SICI)1097-0088(199901)19: $1<59::$ AID-JOC347>3.0.CO;2-B.

L'Heureux, M. L., and D. W. J. Thompson, 2006: Observed relationships between the El Niño-Southern Oscillation and the extratropical zonal-mean circulation. J. Climate, 19, 276-287, https://doi.org/10.1175/JCLI3617.1.

Liebmann, B., and C. A. Smith, 1996: Description of a complete (interpolated) outgoing longwave radiation dataset. Bull. Amer. Meteor. Soc., 77, 1275-1277, https://doi.org/10.1175/ 1520-0477-77.6.1274.

Lindesay, J. A., 1988: South African rainfall, the Southern Oscillation and a Southern Hemisphere semi-annual cycle. J. Climatol., 8, 17-30, https://doi.org/10.1002/joc.3370080103.

Liu, Z., 2012: Dynamics of interdecadal climate variability: A historical perspective. J. Climate, 25, 1963-1995, https://doi.org/ 10.1175/2011JCLI3980.1.

Lutz, K., J. Jacobeit, and J. Rathmann, 2015: Atlantic warm and cold water events and impact on African west coast precipitation. Int. J. Climatol., 35, 128-141, https://doi.org/10.1002/ joc.3969.

Lyon, B., and S. J. Mason, 2007: The 1997-98 summer rainfall season in southern Africa. Part I: Observations. J. Climate, 20, 5134-5148, https://doi.org/10.1175/JCLI4225.1.

_, and - 2009: The 1997/98 summer rainfall season in southern Africa. Part II: Model simulations and coupled mode forecasts. J. Climate, 22, 3802-3818, https://doi.org/10.1175/ 2009JCLI2600.1. 
Macron, C., B. Pohl, Y. Richard, and M. Bessafi, 2014: How do tropical temperate troughs form and develop over southern Africa? J. Climate, 27, 1633-1647, https://doi.org/10.1175/ JCLI-D-13-00175.1.

_, Y. Richard, T. Garot, M. Bessafi, B. Pohl, A. Ratiarison, and A. Razafindrabe, 2016: Intraseasonal rainfall variability over Madagascar. Mon. Wea. Rev., 144, 1877-1885, https://doi.org/ 10.1175/MWR-D-15-0077.1.

Madden, R. A., and P. R. Julian, 1994: Observations of the 40-50-day tropical oscillation-A review. Mon. Wea. Rev., 122, 814-837, https://doi.org/10.1175/1520-0493(1994)122<0814: OOTDTO $>2.0 . \mathrm{CO} ; 2$.

Malherbe, J., F. A. Engelbrecht, W. A. Landman, and C. J. Engelbrecht, 2012: Tropical systems from the southwest Indian Ocean making landfall over the Limpopo River basin, southern Africa: A historical perspective. Int. J. Climatol., 32, 1018-1032, https://doi.org/10.1002/joc.2320.

, W. A. Landman, and F. A. Engelbrecht, 2014: The bi-decadal rainfall cycle, southern annular mode and tropical cyclones over the Limpopo River basin, southern Africa. Climate Dyn., 42, 3121-3138, https://doi.org/10.1007/s00382-013-2027-y.

_ B. Dieppois, P. Maluleke, M. Van Staden, and D. L. Pillay, 2016: South African droughts and decadal variability. Nat. Hazards, 80, 657-681, https://doi.org/10.1007/s11069-015-1989-y.

Mantua, N. J., and S. R. Hare, 2002: The Pacific decadal oscillation. J. Oceanogr., 58, 35-44, https://doi.org/10.1023/A:1015820616384.

_, , Y. Zhang, J. M. Wallace, and R. C. Francis, 1997: A Pacific interdecadal climate oscillation with impacts on salmon production. Bull. Amer. Meteor. Soc., 78, 1069-1080, https:// doi.org/10.1175/1520-0477(1997)078<1069:APICOW>2.0.CO;2.

Mason, S. J., 1990: Temporal variability of sea surface temperatures around southern Africa: A possible forcing mechanism for eighteen-year rainfall oscillation? S. Afr. J. Sci., 86, 243-252.

_ 1995: Sea-surface temperature-South African rainfall associations, 1910-1989. Int. J. Climatol., 15, 119-135, https:// doi.org/10.1002/joc.3370150202.

_ , and M. R. Jury, 1997: Climatic variability and change over southern Africa: A reflection on underlying processes. Prog. Phys. Geogr., 21, 23-50, https://doi.org/10.1177/ 030913339702100103.

Masupha, T. E., M. E. Moeletsi, and M. Tsubo, 2016: Dry spells assessment with reference to the maize crop in the Luvuvhu River catchment of South Africa. Phys. Chem. Earth, 92, 99-111, https://doi.org/10.1016/j.pce.2015.10.014.

Meehl, G. A., A. Hu, B. D. Santer, and S.-P. Xie, 2016: Contribution of the interdecadal Pacific oscillation to twentiethcentury global surface temperature trends. Nat. Climate Change, 6, 1005-1008, https://doi.org/10.1038/nclimate3107.

Michelangeli, P.-A., R. Vautard, and B. Legras, 1995: Weather regimes: Recurrence and quasi stationarity. J. Atmos. Sci., 52, 1237-1256, https://doi.org/10.1175/1520-0469(1995)052<1237: WRRAQS $>2.0 . \mathrm{CO} ; 2$.

Misra, V., 2003: The influence of Pacific SST variability on the precipitation over southern Africa. J. Climate, 16, 2408-2418, https://doi.org/10.1175/2785.1.

Morioka, Y., T. Tozuka, S. Masson, P. Terray, J.-J. Luo, and T. Yamagata, 2012: Subtropical dipole modes simulated in a coupled general circulation model. J. Climate, 25, 4029-4047, https://doi.org/10.1175/JCLI-D-11-00396.1.

Mulenga, H. M., M. Rouault, and C. J. C. Reason, 2003: Dry summers over northeastern South Africa and associated circulation anomalies. Climate Res., 25, 29-41, https://doi.org/ $10.3354 / \mathrm{cr} 025029$.
Munday, C., and R. Washington, 2017: Circulation controls on southern African precipitation in coupled models: The role of the Angola low. J. Geophys. Res. Atmos., 122, 861-877, https:// doi.org/10.1002/2016JD025736.

Newman, M., and Coauthors, 2016: The Pacific decadal oscillation, revisited. J. Climate, 29, 4399-4427, https://doi.org/10.1175/ JCLI-D-15-0508.1.

Nicholson, S. E., 1997: An analysis of the ENSO signal in the tropical Atlantic and western Indian Oceans. Int. J. Climatol., 17, 345-375, https://doi.org/10.1002/(SICI)1097-0088(19970330)17: 4<345::AID-JOC127>3.0.CO;2-3.

—_, and J. Kim, 1997: The relationship of the El Niño-Southern Oscillation to African rainfall. Int. J. Climatol., 17, 117-135, https://doi.org/10.1002/(SICI)1097-0088(199702)17:2<117:: AID-JOC84>3.0.CO;2-O.

Oettli, P., T. Tozuka, T. Izumo, F. A. Engelbrecht, and T. Yamagata, 2014: The self-organizing map, a new approach to apprehend the Madden-Julian oscillation influence on the intraseasonal variability of rainfall in the southern African region. Climate Dyn., 43, 1557-1573, https://doi.org/10.1007/s00382-013-1985-4.

Parker, D., C. Folland, A. Scaife, J. Knight, A. Colman, P. Baines, and B. Dong, 2007: Decadal to multidecadal variability and the climate change background. J. Geophys. Res., 112, D18115, https://doi.org/10.1029/2007JD008411.

Philippon, N., M. Rouault, Y. Richard, and A. Favre, 2012: The influence of ENSO on winter rainfall in South Africa. Int. J. Climatol., 32, 2333-2347, https://doi.org/10.1002/joc.3403.

Poccard, I., S. Janicot, and P. Camberlin, 2000: Comparison of rainfall structures between NCEP/NCAR reanalyses and observed data over tropical Africa. Climate Dyn., 16, 897-915, https://doi.org/10.1007/s003820000087.

Pohl, B., and H. Douville, 2011: Diagnosing GCM errors over West Africa using relaxation experiments. Part II: Intraseasonal variability and African easterly waves. Climate Dyn., 37, 13131334, https://doi.org/10.1007/s00382-011-1106-1.

— , and N. Fauchereau, 2012: The southern annular mode seen through weather regimes. J. Climate, 25, 3336-3354, https:// doi.org/10.1175/JCLI-D-11-00160.1.

—, Y. Richard, and N. Fauchereau, 2007: Influence of the MaddenJulian oscillation on southern African summer rainfall. J. Climate, 20, 4227-4242, https://doi.org/10.1175/JCLI4231.1.

, N. Fauchereau, Y. Richard, M. Rouault, and C. J. C. Reason, 2009: Interactions between synoptic, intraseasonal and interannual convective variability over southern Africa. Climate Dyn., 33, 1033-1050, https://doi.org/10.1007/s00382-008-0485-4.

- - C. J. C. Reason, and M. Rouault, 2010: Relationships between the Antarctic Oscillation, the Madden-Julian oscillation, and ENSO, and consequences for rainfall analysis. J. Climate, 23, 238-254, https://doi.org/10.1175/2009JCLI2443.1.

Power, S., T. Casey, C. Folland, A. Colman, and V. Mehta, 1999: Interdecadal modulation of the impact of ENSO on Australia. Climate Dyn., 15, 319-324, https://doi.org/10.1007/s003820050284.

Ratna, S. B., S. Behera, J. V. Ratnam, K. Takahashi, and T. Yamagata, 2013: An index for tropical temperate troughs over southern Africa. Climate Dyn., 41, 421-441, https://doi.org/ 10.1007/s00382-012-1540-8.

Reason, C. J. C., 1998: Warm and cold events in the southeast Atlantic/southwest Indian Ocean region and potential impacts on circulation and rainfall over southern Africa. Meteor. Atmos. Phys., 69, 49-65, https://doi.org/10.1007/BF01025183.

, 2001: Subtropical Indian Ocean SST dipole events and southern African rainfall. Geophys. Res. Lett., 28, 2225-2227, https://doi.org/10.1029/2000GL012735. 
_ 2002: Sensitivity of the southern African circulation to dipole sea-surface temperature patterns in the south Indian Ocean. Int. J. Climatol., 22, 377-393, https://doi.org/10.1002/joc.744.

- and H. Mulenga, 1999: Relationships between South African rainfall and SST anomalies in the southwest Indian Ocean. Int. J. Climatol., 19, 1651-1673, https://doi.org/10.1002/(SICI) 1097-0088(199912)19:15<1651::AID-JOC439>3.0.CO;2-U.

, and M. Rouault, 2002: ENSO-like decadal variability and South African rainfall. Geophys. Res. Lett., 29, 1638, https:// doi.org/10.1029/2002GL014663.

— , and A. Keibel, 2004: Tropical Cyclone Eline and its unusual penetration and impacts over the southern African mainland. Wea. Forecasting, 19, 789-805, https://doi.org/10.1175/15200434(2004)019<0789:TCEAIU>2.0.CO;2.

— , and D. Jagadheesha, 2005: A model investigation of recent ENSO impacts over southern Africa. Meteor. Atmos. Phys., 89, 181-205, https://doi.org/10.1007/s00703-005-0128-9.

_- and S. Smart, 2015: Tropical south east Atlantic warm events and associated rainfall anomalies over southern Africa. Front. Environ. Sci., 3, 24, https://doi.org/10.3389/fenvs.2015.00024.

—, R. J. Allan, J. A. Lindesay, and T. J. Ansell, 2000: ENSO and climatic signals across the Indian Ocean Basin in the global context: Part I, interannual composite patterns. Int. J. Climatol., 20, 1285-1327, https://doi.org/10.1002/1097-0088(200009)20: $11<1285::$ AID-JOC536>3.0.CO;2-R.

—, S. Hachigonta, and R. F. Phaladi, 2005: Interannual variability in rainy season characteristics over the Limpopo region of southern Africa. Int. J. Climatol., 25, 1835-1853, https:// doi.org/10.1002/joc.1228.

Reynolds, R. W., N. A. Rayner, T. M. Smith, D. C. Stokes, and W. Wang, 2002: An improved in situ and satellite SST analysis for climate. J. Climate, 15, 1609-1625, https://doi.org/10.1175/ 1520-0442(2002)015<1609:AIISAS > 2.0.CO;2.

Richard, Y., S. Trzaska, P. Roucou, and M. Rouault, 2000: Modification of the southern African rainfall variability/ENSO relationship since the late 1960s. Climate Dyn., 16, 883-895, https://doi.org/10.1007/s003820000086.

—, N. Fauchereau, I. Poccard, M. Rouault, and S. Trzaska, 2001: 20th century droughts in southern Africa: Spatial and temporal variability, teleconnections with oceanic and atmospheric conditions. Int. J. Climatol., 21, 873-885, https://doi.org/ 10.1002/joc.656.

Rouault, M., P. Florenchie, N. Fauchereau, and C. J. C. Reason, 2003: South east tropical Atlantic warm events and southern African rainfall. Geophys. Res. Lett., 30, 8009, https://doi.org/ 10.1029/2002GL014840.

— J. Servain, C. J. C. Reason, B. Bourlès, M. J. Rouault, and N. Fauchereau, 2009: Extension of PIRATA in the tropical south-east Atlantic: An initial one-year experiment. Afr. J. Mar. Sci., 31, 63-71, https://doi.org/10.2989/AJMS.2009.31.1.5.776.

Seager, R., N. Harnik, Y. Kushnir, W. Robinson, and J. Miller, 2003: Mechanisms of hemispherically symmetric variability. J. Climate, 16, 2960-2978, https://doi.org/10.1175/ 1520-0442(2003)016<2960:MOHSCV > 2.0.CO;2.

Singleton, A. T., and C. J. C. Reason, 2007a: Variability in the characteristics of cut-off low pressure systems over subtropical southern Africa. Int. J. Climatol., 27, 295-310, https://doi.org/ $10.1002 /$ joc. 1399 .

— and - 2007b: A numerical model study of an intense cutoff low pressure system over South Africa. Mon. Wea. Rev., 135, 1128-1150, https://doi.org/10.1175/MWR3311.1.

Sturaro, G., 2003: A closer look at the climatological discontinuities present in the NCEP/NCAR reanalysis temperature due to the introduction of satellite data. Climate Dyn., 21, 309-316, https://doi.org/10.1007/s00382-003-0334-4.

Tennant, W. J., and B. C. Hewitson, 2002: Intra-seasonal rainfall characteristics and their importance to the seasonal prediction problem. Int. J. Climatol., 22, 1033-1048, https://doi.org/ 10.1002/joc.778.

Tim, N., E. Zorita, and B. Hünicke, 2015: Decadal variability and trends of the Benguela upwelling system as simulated in a high-resolution ocean simulation. Ocean Sci., 11, 483-502, https://doi.org/10.5194/os-11-483-2015.

Todd, M., and R. Washington, 1999: Circulation anomalies associated with tropical-temperate troughs in southern Africa and the south west Indian Ocean. Climate Dyn., 15, 937-951, https://doi.org/10.1007/s003820050323.

$\longrightarrow,-$, and P. I. Palmer, 2004: Water vapour transport associated with tropical-temperate trough systems over southern Africa and the southwest Indian Ocean. Int. J. Climatol., 24, 555-568, https://doi.org/10.1002/joc.1023.

Trenberth, K. E., D. P. Stepaniak, J. W. Hurrell, and M. Fiorino, 2001: Quality of reanalyses in the tropics. J. Climate, 14, 1499-1510, https://doi.org/10.1175/1520-0442(2001)014<1499: QORITT $>2.0 . \mathrm{CO} ; 2$.

Tyson, P. D., 1981: Atmospheric circulation variations and the occurrence of extended wet and dry spells over southern Africa. J. Climatol., 1, 115-130, https://doi.org/10.1002/ joc. 3370010203 .

Usman, M. T., and C. J. C. Reason, 2004: Dry spell frequencies and their variability over southern Africa. Climate Res., 26, 199-211, https://doi.org/10.3354/cr026199.

Vigaud, N., B. Pohl, and J. Crétat, 2012: Tropical-temperate interactions over southern Africa simulated by a regional climate model. Climate Dyn., 39, 2895-2916, https://doi.org/ 10.1007/s00382-012-1314-3.

Washington, R., and M. Todd, 1999: Tropical-temperate links in southern African and southwest Indian Ocean satellite-derived daily rainfall. Int. J. Climatol., 19, 16011616, https://doi.org/10.1002/(SICI)1097-0088(19991130)19: 14<1601::AID-JOC407>3.0.CO;2-0. , and A. Preston, 2006: Extreme wet years over southern Africa: Role of Indian Ocean sea surface temperatures. J. Geophys. Res., 111, D15104, https://doi.org/10.1029/2005JD006724.

Wu, Z., N. E. Huang, S. R. Long, and C.-K. Peng, 2007: On the trend, detrending, and variability of nonlinear and nonstationary time series. Proc. Natl. Acad. Sci. USA, 104, 14889 14 894, https://doi.org/10.1073/pnas.0701020104.

Zhang, C., 2005: Madden-Julian oscillation. Rev. Geophys., 43, RG2003, https://doi.org/10.1029/2004RG000158.

Zhang, Y., J. M. Wallace, and D. S. Battisti, 1997: ENSO-like interdecadal variability: 1900-93. J. Climate, 10, 1004-1020, https:// doi.org/10.1175/1520-0442(1997)010<1004:ELIV>2.0.CO;2. 